\title{
A Network Pharmacology Study on the Molecular Mechanisms of FDY003 for Breast Cancer Treatment
}

\author{
Ho-Sung Lee, ${ }^{1,2}$ In-Hee Lee, ${ }^{1}$ Kyungrae Kang, ${ }^{2}$ Sang-In Park, ${ }^{3}$ Seung-Joon Moon, ${ }^{2}$ \\ Chol Hee Lee, ${ }^{2}$ and Dae-Yeon Lee $\mathbb{B}^{1,2}$ \\ ${ }^{1}$ The Fore, 87 Ogeum-ro, Songpa-gu, Seoul 05542, Republic of Korea \\ ${ }^{2}$ Forest Hospital, 129 Ogeum-ro, Songpa-gu, Seoul 05549, Republic of Korea \\ ${ }^{3}$ Forestheal Hospital, 173 Ogeum-ro, Songpa-gu, Seoul 05641, Republic of Korea
}

Correspondence should be addressed to Dae-Yeon Lee; foresthrnd@gmail.com

Received 29 May 2020; Revised 25 January 2021; Accepted 29 January 2021; Published 6 February 2021

Academic Editor: Azis Saifudin

Copyright (c) 2021 Ho-Sung Lee et al. This is an open access article distributed under the Creative Commons Attribution License, which permits unrestricted use, distribution, and reproduction in any medium, provided the original work is properly cited.

Herbal medicines have drawn considerable attention with regard to their potential applications in breast cancer (BC) treatment, a frequently diagnosed malignant disease, considering their anticancer efficacy with relatively less adverse effects. However, their mechanisms of systemic action have not been understood comprehensively. Based on network pharmacology approaches, we attempted to unveil the mechanisms of FDY003, an herbal drug comprised of Lonicera japonica Thunberg, Artemisia capillaris Thunberg, and Cordyceps militaris, against BC at a systemic level. We found that FDY003 exhibited pharmacological effects on human BC cells. Subsequently, detailed data regarding the biochemical components contained in FDY003 were obtained from comprehensive herbal medicine-related databases, including TCMSP and CancerHSP. By evaluating their pharmacokinetic properties, 18 chemical compounds in FDY003 were shown to be potentially active constituents interacting with 140 BC-associated therapeutic targets to produce the pharmacological activity. Gene ontology enrichment analysis using g:Profiler indicated that the FDY003 targets were involved in the modulation of cellular processes, involving the cell proliferation, cell cycle process, and cell apoptosis. Based on a KEGG pathway enrichment analysis, we further revealed that a variety of oncogenic pathways that play key roles in the pathology of BC were significantly enriched with the therapeutic targets of FDY003; these included PI3K-Akt, MAPK, focal adhesion, FoxO, TNF, and estrogen signaling pathways. Here, we present a network-perspective of the molecular mechanisms via which herbal drugs treat BC.

\section{Introduction}

Breast cancer (BC) is a common female malignancy and a cause of mortality globally [1]. The genetic and epigenetic dysregulations in multiple cancer-associated genes and their key oncogenic signalings are implicated in the pathology of $\mathrm{BC}$; these include the phosphoinositide 3-kinase- (PI3K-) Akt, tumor necrosis factor (TNF), forkhead box O (FoxO), erythroblastic leukemia viral oncogene homolog (ErbB), vascular endothelial growth factor (VEGF), hypoxia-inducible factor- (HIF-) 1, estrogen, p53, focal adhesion, and mitogen-activated protein kinase (MAPK) pathways [2-4]. Currently, chemotherapy, molecular-targeted therapy, and endocrine therapy are the major pharmacological approaches for $\mathrm{BC}$ treatment [5-10]. However, the longterm and frequent use of the aforementioned therapeutic drugs may induce toxic events that deteriorate quality of life of cancer patients, including gastrointestinal dysfunction, fatigue, peripheral neuropathy, immunosuppression and myelosuppression, cardiotoxicity, and osteoporosis [11-18]. In addition, the pharmacological efficacy of most moleculartargeted agents often falls short of expectations because of their limited capacity to therapeutically modulate the cancerous activities of various oncogenic cellular components [19]. These issues emphasize the need for anticancer agents that can pharmacologically regulate multiple oncogenes and pathways with safety. Herbal drugs are multicomponent therapeutics that elicit their pharmacological effects via 
multiple chemical compounds that target diverse diseaserelated genes, proteins, and pathways [20, 21]. Herbal medicines have attracted much attention due to their promising anticancer effects, reduced toxicities, and lower side effects [20, 21]. Previous clinical research studies have further shown that the use of herbal drugs can improve the tumor response, survival, health status, and quality of life of patients undergoing cancer therapy [22, 23].

FDY003 is an herbal formula composed of three herbal medicines [24, 25], namely, Lonicera japonica Thunberg (LjT), Artemisia capillaris Thunberg (AcT), and Cordyceps militaris $(\mathrm{Cm})$, that have been reported to exert prominent anticancer effects in various cancer types [26-35]. It has been shown that FDY003 is a potent inhibitor of proliferation while promoting the apoptotic death of cancer cells and tumors [24, 25]. These activities involve regulation of key modulators of cell cycle and apoptosis, such as p53, p21, caspase-3, and Bcl-2-associated X protein (Bax) [24]. However, the molecular mechanisms of FDY003 against BC at the systemic level remain unclear.

Network pharmacology is a multidisciplinary research approach that uncovers complex disease mechanisms and can be used to formulate promising treatment strategies based on a systems perspective [36-39]. The interdisciplinary methodology integrates diverse scientific fields, such as medicine, pharmacology, network biology, systems biology, and computer science [36-39]. Network pharmacology has been demonstrated to be an efficient tool for the acquisition of comprehensive and systematic insights into the "multicompound, multitarget, multipathway" polypharmacological properties of herbal medicines, and it is extensively used to explore the active chemical compounds of herbal drugs and their therapeutic targets responsible for their pharmacological activities [36-39]. Network pharmacology investigates how associated systematic mechanisms are regulated through interactions among various key components and targets [36-39]. Here, we attempted to unravel the molecular mechanisms of anti-BC effects of FDY003 based on network pharmacology approaches.

\section{Materials and Methods}

2.1. Cell Culture. The MCF-7, MDA-MB-453, and MDAMB-231 human BC cell lines were purchased from the Korean Cell Line Bank (Seoul, Korea). The cells were cultured in Dulbecco's Modified Eagle's Medium (DMEM, WELGENE Inc., Daegu, Korea) supplemented with 10\% fetal bovine serum, $100 \mathrm{U} / \mathrm{mL}$ penicillin, and $100 \mu \mathrm{g} / \mathrm{mL}$ streptomycin (Thermo Fisher Scientific Inc., Waltham, MA, USA). The cultured cells were maintained in a humidified atmosphere with $5 \% \mathrm{CO}_{2}$ at $37^{\circ} \mathrm{C}$.

2.2. Preparation of FDY003 Herbal Formula. The preparation of FDY003 was conducted as previously described [25]. In brief, the raw herbal constituents of FDY003 were obtained from Green Myeong-Poom Pharm. Co., Ltd. (Namyangju, Korea). The dried plant materials of LjT (4.16g), AcT $(6.25 \mathrm{~g})$, and $\mathrm{Cm}(6.25 \mathrm{~g})$ were ground, added to $70 \%$ ethanol
$(500 \mathrm{~mL})$, and subjected to reflux extraction at $80^{\circ} \mathrm{C}$ for $3 \mathrm{~h}$. Then, the herbal extract was filtered through a $1 \mu \mathrm{m}$ pore filter (Hyundai Micro, Seoul, Korea) and successively purified with $80 \%$ and $90 \%$ ethanol. The resulting solution was lyophilized at $-80^{\circ} \mathrm{C}$. The samples were stored at $-20^{\circ} \mathrm{C}$ and then dissolved in distilled water before the experiments.

2.3. Cell Viability Assay. The cell viability assay was performed following the previous procedures [25]. 3-(4,5-Dimethylthiazol-2-yl)-2,5-diphenyltetrazolium bromide (MTT) was obtained from Sigma-Aldrich Inc. (St. Louis, MO, USA). Cell viability was measured using the MTT assay. The cells were seeded in 96 -well plates $\left(5.0 \times 10^{4}\right.$ cells per well) and then treated with the indicated drugs for $72 \mathrm{~h}$ in a $5 \% \mathrm{CO}_{2}$ incubator at $37^{\circ} \mathrm{C}$. Subsequently, MTT solution $(200 \mu \mathrm{L})$ was added to each well, and the cells were further incubated for $2 \mathrm{~h}$. Thereafter, the resulting formazan crystals were dissolved in dimethyl sulfoxide, and the absorbance was read with an Epoch 2 Microplate Spectrophotometer at $550 \mathrm{~nm}$ (BioTek, Winooski, VT, USA).

\subsection{Exploration of Active Chemical Compounds.} Comprehensive information on the phytochemical components of FDY003 was integrated from traditional Chinese medicine systems pharmacology (TCMSP) and anticancer herbs database of systems pharmacology (CancerHSP) databases $[40,41]$. To determine the bioactive compounds of FDY003, we assessed the key absorption, distribution, metabolism, and excretion (ADME) pharmacokinetic parameters (i.e., oral bioavailability (OB), drug-likeness (DL), and Caco-2 permeability) of chemical constituents obtained from the TCMSP database [40]. OB, a pivotal consideration in drug development, is a measurement of the rate, fraction, and extent of an orally administered drug that reaches the expected site of drug action $[40,42]$. Caco- 2 permeability is a parameter widely used for the evaluation of the intestinal absorption rate and extent of a given substance using Caco- 2 human intestinal epithelial cells [40, 43-45]. In general, drug molecules with a Caco- 2 permeability less than -0.4 are considered not permeable across the epithelium of intestines $[40,46,47]$. DL is an indicator that is used to assess whether a compound has the potential to be developed into a drug with respect to its physical and chemical properties; it is calculated based on the Tanimoto coefficient and relevant molecular descriptors [40, 48]. A chemical compound is considered active if it meets the following criteria: $\mathrm{OB} \geq 30 \%$, Caco-2 permeability $\geq-0.4$, and $\mathrm{DL} \geq 0.18[37,40,49,50]$.

2.5. Target Identification for the Active Compounds. Molecular targets of the bioactive compounds of FDY003 were determined using comprehensive information regarding chemical-protein interactions obtained from various relevant databases, including Search Tool for Interactions of Chemicals (STITCH) 5 [51], SwissTargetPrediction [52, 53], PharmMapper [54], and Similarity Ensemble Approach (SEA) [55]. We also used in silico models, such as systematic drug targeting tool (SysDT) [56] 
and weighted ensemble similarity (WES) algorithm [57], for target identification according to previously described procedures [58-63]. Human genes/proteins related to the pathology of $\mathrm{BC}$ were obtained from the following databases: Therapeutic Target Database (TTD) [64], GeneCards [65], Comparative Toxicogenomics Database (CTD) [66], DisGeNET [67], Human Genome Epidemiology (HuGE) Navigator [68], Online Mendelian Inheritance in Man (OMIM) [69], Pharmacogenomics Knowledgebase (PharmGKB) [70], and DrugBank [71].

2.6. Network Construction. The herbal medicine-bioactive compound $(\mathrm{H}-\mathrm{C})$ and bioactive compound-target $(\mathrm{C}-\mathrm{T})$ networks were generated by connecting the three herbal constituents of FDY003 with the bioactive compounds and the bioactive compounds with the targets. The targetpathway (T-P) network was generated by connecting the targets with relevant biological pathways. The proteinprotein interaction (PPI) network was generated based on the interactions between the targets (confidence score$\geq 0.9$ ) using the STRING database [72]. Network visualization and analysis were performed with Cytoscape [73]. In the presented data, nodes indicate the herbal constituents, active chemical constituents, targets, or pathways, and edges (or links) indicate their interactions [74]. The degree indicates the number of edges of a node in a network [74].

2.7. Contribution Index Analysis. The contribution of chemical compounds to the pharmacological activity of FDY003 was analyzed using a contribution index (CI) [50] that can be calculated using the following formula:

$$
\begin{aligned}
\mathrm{NE}(j) & =\sum_{i=1}^{n} d_{i}, \\
\mathrm{CI}(j) & =\frac{c_{j} \times \mathrm{NE}(j)}{\sum_{i=1}^{m} c_{i} \times \mathrm{NE}(i)} \times 100 \%,
\end{aligned}
$$

twhere NE indicates the network-based efficacy, $n$ indicates the number of targets of chemical component $j, d_{i}$ indicates the number of links of target $i$ of chemical component $j, m$ indicates the number of chemical components, and $c_{i}$ (or $c_{j}$ ) indicates the number of previous literatures containing the terms "breast cancer" and the common name of chemical component $i$ (or $j$ ) in their title or abstract that were retrieved from the PubMed (https:// pubmed.ncbi.nlm.nih.gov/). If the sum of the highest CIs is greater than $85 \%$, the compounds with those CIs are considered the major contributors, as previously suggested [50].

2.8. Functional Enrichment Analysis. Gene ontology (GO) enrichment analysis was performed using g:Profiler [75], and pathway enrichment analysis was carried out with Kyoto Encyclopedia of Genes and Genomes (KEGG) databases [76].

\section{Results}

3.1. Anticancer Properties of FDY003 against Breast Cancer. To investigate whether FDY003 exerts therapeutic effects on BC cells, we treated MCF-7 (an estrogen receptor-positive human BC cell line), MDA-MB-453 (a human epidermal growth factor receptor 2- (HER2-) positive human BC cell line), and MDAMB-231 (a triple-negative human BC cell line) cells with FDY003 for $72 \mathrm{~h}$ and observed their responses. We found that FDY003 repressed the viability of MCF-7 $\left(\mathrm{IC}_{50}=242.90 \mu \mathrm{g} /\right.$ $\mathrm{mL}), \mathrm{MDA}-\mathrm{MB}-453\left(\mathrm{IC}_{50}=156.01 \mu \mathrm{g} / \mathrm{mL}\right)$, and MDA-MB-231 $\left(\mathrm{IC}_{50}=197.56 \mu \mathrm{g} / \mathrm{mL}\right)$ cells (Supplementary Figure S1), suggesting that the herbal medicine possesses anti-BC properties.

3.2. Chemical Components of FDY003. The chemical compounds that are present in FDY003 were obtained from the comprehensive databases associated with herbal medicine such as TCMSP and CancerHSP [40, 41]. Accordingly, 323 compounds were retrieved for FDY003 after removing duplicates (Supplementary Table S1).

3.3. Active Chemical Compounds in FDY003. Compounds whose pharmacokinetic parameters met the following criteria were considered active as described in Section 2.4: $\mathrm{OB} \geq 30 \%$, Caco- 2 permeability $\geq-0.4$, and $\mathrm{DL} \geq 0.18$ $[49,50]$. A number of compounds not satisfying the aforementioned criteria were also considered bioactive because they were present in large amounts in herbal medicines and were known to have potent pharmacological efficacy. As a result, we obtained 20 active compounds for FDY003 (Supplementary Table S2).

3.4. Targets of Active Chemical Compounds in FDY003. We used comprehensive chemical-protein interaction data obtained from various relevant databases, including STITCH [51], SEA [55], SwissTargetPrediction [52, 53], and PharmMapper [54] to explore the molecular targets for the bioactive chemical components in FDY003. In addition, in silico models, such as SysDT [56] and WES algorithms [57], were used for the target exploration based on previously described procedures [58-63]. Consequently, we obtained 196 targets for the 18 active compounds (i.e., 4'-methylcapillarisin, arcapillin, artepillin A, capillarisin, chrysoeriol, cirsimaritin, cordycepin, corymbosin, eriodyctiol (flavanone), eupalitin, eupatolitin, genkwanin, isoarcapillin, isorhamnetin, kaempferol, luteolin, quercetin, and $\beta$-sitosterol) in FDY003 (Figure 1 and Supplementary Table S3). No interacting targets were retrieved for the compounds "loniceracetalides B_qt" and "demethoxycapillarisin."

3.5. Network Pharmacology Study on the Molecular Mechanisms of FDY003. To conduct network pharmacology analysis of the molecular mechanisms of FDY003 against $\mathrm{BC}$, we first generated an herbal medicine-bioactive compound-target (H-C-T) network of the herbal formula by linking the herbal medicines with their bioactive chemical components and the components with the targets (Figure 2). 


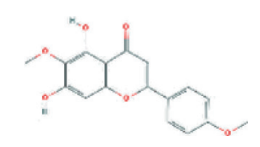

1. $4^{\prime}$-Methylcapillarisin

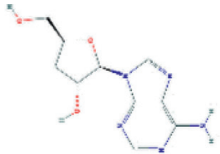

7. Cordycepin

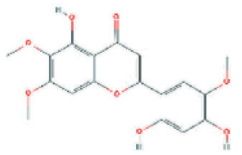

2. Arcapillin

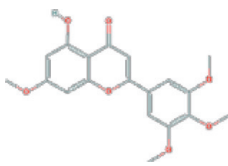

8. Corymbosin

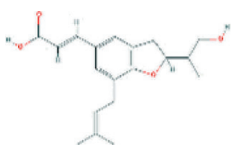

3. Artepillin A

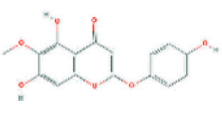

4. Capillarisin

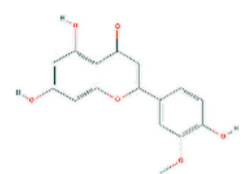

5. Chrysoeriol

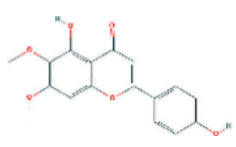

6. Cirsimaritin<smiles>CC1CC(C)C(C2CC(C)C(C)CC2I)CC1C</smiles>

13. Isoarcapillin

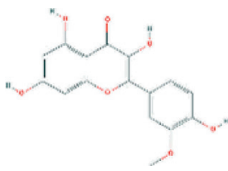

14. Isorhamnetin

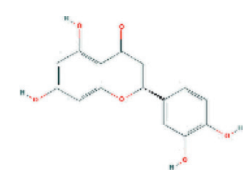

9. Eriodyctiol (flavanone)<smiles>CCC(CC)CCC(CCCC(CC)C(CC)CC)C(C)C(C)C</smiles>

10. Eupalitin

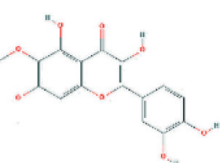

11. Eupatolitin

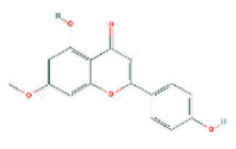

12. Genkwanin

Figure 1: The active chemical compounds of FDY003.

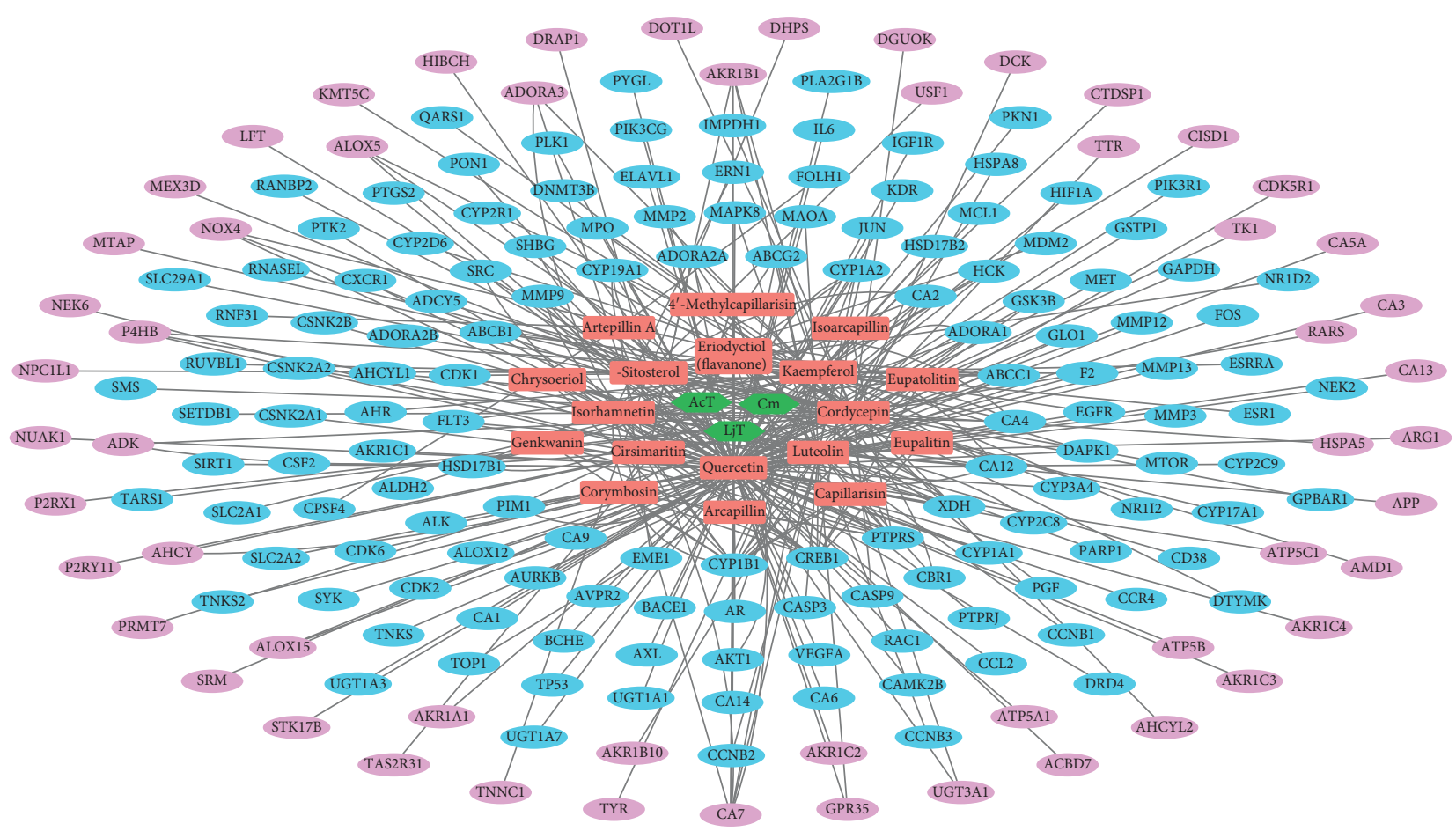

FIGURE 2: Herbal medicine-active chemical compound-target network of FDY003. Green hexagons, herbal medicines; red rectangles, active chemical compounds; blue ellipses, $\mathrm{BC}$-associated targets; purple ellipses, non-BC-associated targets.

The resulting $\mathrm{H}-\mathrm{C}-\mathrm{T}$ network contained 217 nodes (3 herbal medicines, 18 active chemical components, and 196 targets) and 354 edges (Figure 2). In addition, to obtain insight into the $\mathrm{BC}$-associated pharmacological features of FDY003, we constructed a C-T network (158 nodes with 254 edges) by connecting the bioactive chemical components with the BC-associated targets (Figure 3 and Supplementary Table S3). The quercetin, luteolin, kaempferol, cordycepin, eriodyctiol (flavanone), isorhamnetin, and $\beta$-sitosterol exhibited the highest degrees (Figure 3 and Supplementary Table S3), implying that they are essential for the mediation of the anticancer effects of FDY003 against BC. Furthermore, 42 BC-associated targets interacted with two or more compounds (Figure 3 and Supplementary Table S3), supporting the polypharmacological characteristics of FDY003. 


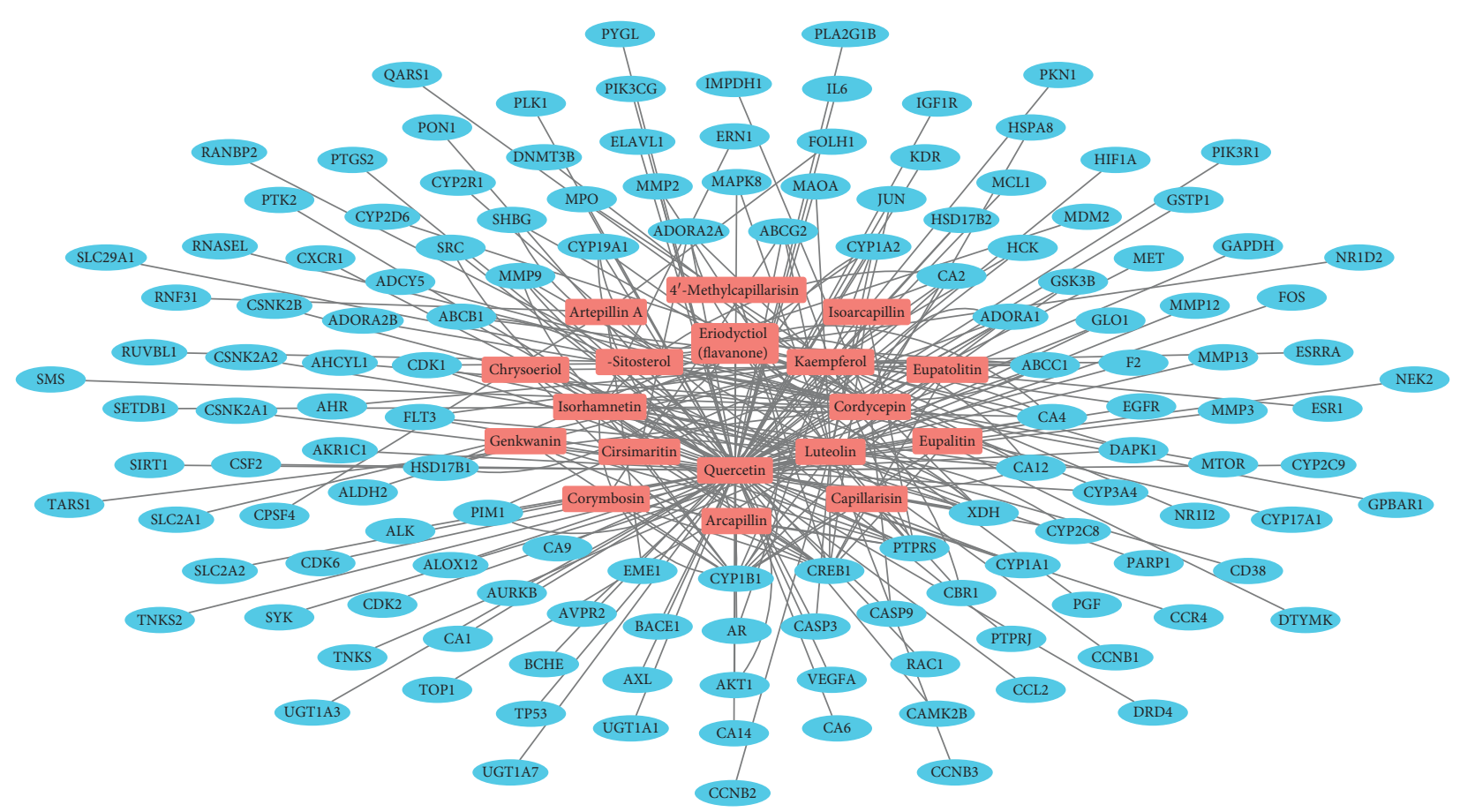

FIGURE 3: Active chemical component-target network of FDY003. Red rectangles, bioactive chemical components; blue ellipses, breast cancer-associated targets.

To investigate the interactive associations among the targets, we built a PPI network (106 nodes and 315 edges) consisting of the BC-associated therapeutic targets of FDY003 (Figure 4). Subsequently, we explored the existence of hubs (i.e., nodes with relatively high degrees that tend to play prominent roles in the cellular processes in a network) $[77,78]$. In the analysis, we defined hubs as nodes with degrees equal to or greater than twice the mean node degree $[79,80]$. Among the BC-associated targets of FDY003, TP53, SRC, PIK3R1, VEGFA, AKT1, EGFR, CYP1A1, CYP3A4, JUN, CDK1, and ESR1 were hub nodes (Figure 4), suggesting that the nodes act as important targets mediating the therapeutic effects of FDY003 against BC cells. Loss of function of p53 (encoded by TP53) due to genetic alterations has been shown to drive the tumorigenesis, progression, and metastasis of $\mathrm{BC}$; p53 expression has been reported to be a potential prognostic indicator for BC patients [81-89]. The dysregulation and elevated activity of the kinase Src (encoded by $S R C$ ) is frequently observed in multiple human malignancies, including $\mathrm{BC}$, and it promotes the invasion, metastasis, migration, and proliferation of BC cells [90-94]. The expression and activity of SRC or PIK3R1 are highly upregulated in malignant breast tumor tissues and have been correlated with decreased survival of BC patients [95-97]. VEGF-A (encoded by VEGFA) is a crucial regulator in the proliferation, angiogenesis, and metastatic behavior of $\mathrm{BC}$ cells, and it confers resistance against chemotherapy [98-101]. The overexpression or hyperactivation of AKT (encoded by $A K T 1$ ), epidermal growth factor receptor (EGFR; encoded by EGFR), or c-Jun (encoded by JUN) promotes various cancerous processes, including proliferation, growth, survival, invasion, and migration of BC cells and is further related to the poorer clinical outcomes of BC patients [102-127]. Such targets have been implicated in reduced drug sensitivity of cancer cells to chemotherapeutics; therefore, targeting them could improve the therapeutic efficacy of chemotherapy and radiotherapy in BC [104-106, 109, 111-113, 117, 119, 123, 125, 126, 128-131]. Cytochrome P450 1A1 (encoded by CYP1A1) and cytochrome P450 3A4 (encoded by CYP3A4) are modulators of estrogen metabolism, and their activities are involved in the cancerous processes of BC cells [132-139]. Genetic polymorphism and expression of CYP3A1 or CYP3A4 in breast tumor tissues have been reported to be potentially useful factors for the prediction of treatment responses to chemotherapy [140, 141]. CDK1 (encoded by CDK1) functions as a crucial regulator in cell cycle progression, and its dysregulation leads to aberrant proliferation of BC cells [142]. Previous studies have indicated that CDK1 activity may act as a prognostic indicator in $\mathrm{BC}$, and CDK1 targeting can increase chemotherapeutic efficacy [143-147]. Abnormal activity of estrogen receptor $\alpha$ (encoded by ESR1) is considered primarily responsible for tumorigenesis and progression of $\mathrm{BC}$, and the receptor is the most promising therapeutic target [134-139].

To assess the contribution of the chemical components to the pharmacological effects of FDY003, we calculated CIs for the individual active compounds (Section 2.7) [50, 148]. As a result, quercetin and luteolin had the highest CIs with a sum of $91.83 \%$ (Supplementary Figure S2), which suggests that the two active components are key factors contributing to the FDY003 anticancer properties in BC treatment.

Overall, the results of the analyses above facilitate the identification of the polypharmacological mechanisms of FDY003 activity against BC. 


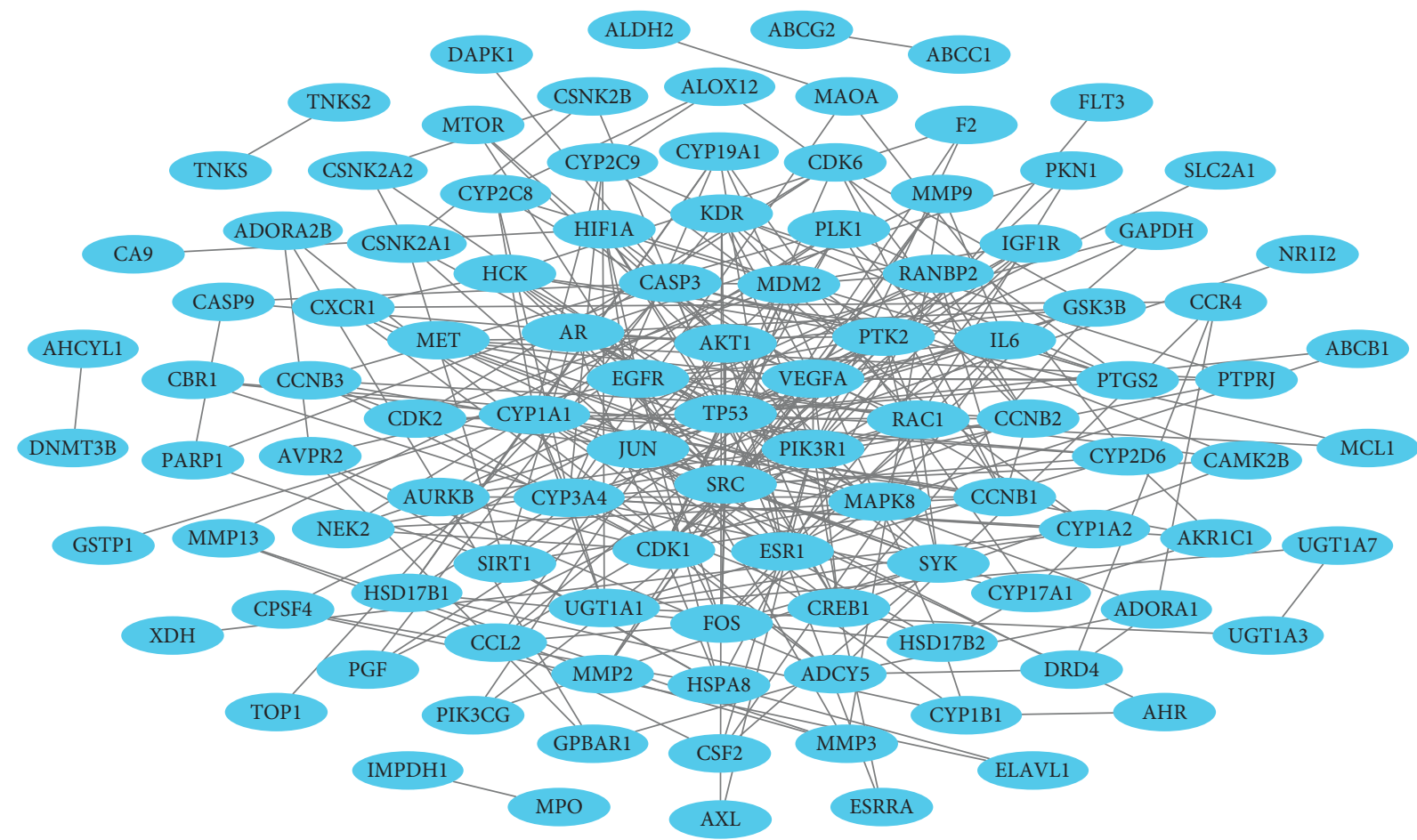

FIGURE 4: Protein-protein interaction network for breast cancer-associated targets of FDY003. Nodes refer to the breast cancer-related targets of FDY003.

3.6. Functional Enrichment Analysis for the FDY003 Network. To investigate the biological roles of the BC-related targets of FDY003, we carried out GO enrichment analysis for the targets. These targets were enriched in GO terms for the modulation of biological processes, involving cell proliferation, cell cycle progression, and cell apoptosis (Supplementary Figure S3), highlighting the molecular properties of FDY003 activity.

The aberrant activities of oncogenic cellular signalings are known to be responsible for cancer development and progression [149]. To this end, we next carried out pathway enrichment analysis for its BC-related targets (Figure 5 and Supplementary Figure S3). We found that the following diverse pathways, which importantly function in the tumorigenesis and progression of BC, were significantly enriched with the FDY003 targets: "Pathways in cancer," "PI3K-Akt signaling pathway," "Endocrine resistance," "MAPK signaling pathway," "Focal adhesion," "Cellular senescence," "FoxO signaling pathway," "TNF signaling pathway," "EGFR tyrosine kinase inhibitor resistance," "Estrogen signaling pathway," "Ras signaling pathway," "Steroid hormone biosynthesis," "Apoptosis," "Breast cancer," "HIF-1 signaling pathway," "PD-L1 expression and PD-1 checkpoint pathway in cancer," "Cell cycle," "ErbB signaling pathway," "Wnt signaling pathway," "p53 signaling pathway," "VEGF signaling pathway," and "Platinum drug resistance" (Figure 5 and Supplementary Figure S3). The dysregulation of PI3K-Akt, MAPK, focal adhesion, and Ras signaling pathways promotes diverse cancerous cell processes, including the uncontrolled cell proliferation, invasion, migration, survival, metastasis, and angiogenesis of
BC cells [3, 126, 150-154]. Abnormalities of crucial cellular function, such as senescence, apoptosis, and cell cycle, are the important pathological processes of $\mathrm{BC}$ [155-160]. The TNF signaling pathway is a mediator of the inflammatory process, and its activity is closely linked with the progression, metastasis, and poor prognosis of BC [161, 162]. The estrogen signaling pathway functions as the most critical regulator of tumor initiation and malignant progression in $\mathrm{BC}$, and therapeutic modulation of its activity serves as a primary treatment strategy [163-167]. Previous studies have suggested that expression of programmed death-ligand 1 (PD-L1) serves as a prognostic factor for the survival of patients with $\mathrm{BC}$ and that inhibition of the programmed cell death protein 1 (PD-1)/PD-L1 pathway can enhance antitumor responses [168-172]. The HIF-1 and Wnt signaling regulate various cellular behaviors, involving cell proliferation, metastasis, and stem cell-like characteristics in BC cells [173-180]. The p53 signaling pathway exerts tumorsuppressive activity associated with cell cycle arrest, apoptosis, and cellular senescence, and loss of function of its key pathway components has been implicated in the carcinogenesis of $\mathrm{BC}$ and is a negative prognostic factor for patient survival $[85,181]$. The VEGF signaling pathway plays a protumoral role by increasing angiogenesis, thus promoting the survival, migration, and invasion of BC cells [101, 182]. In addition, resistance to platinum-based drugs, endocrine therapy, and EGFR signaling inhibitors are major obstacles in BC treatment [183-189].

We further analyzed the functional associations among FDY003 targets using GeneMANIA [190], an algorithm useful for the analysis of biological functions of cellular 


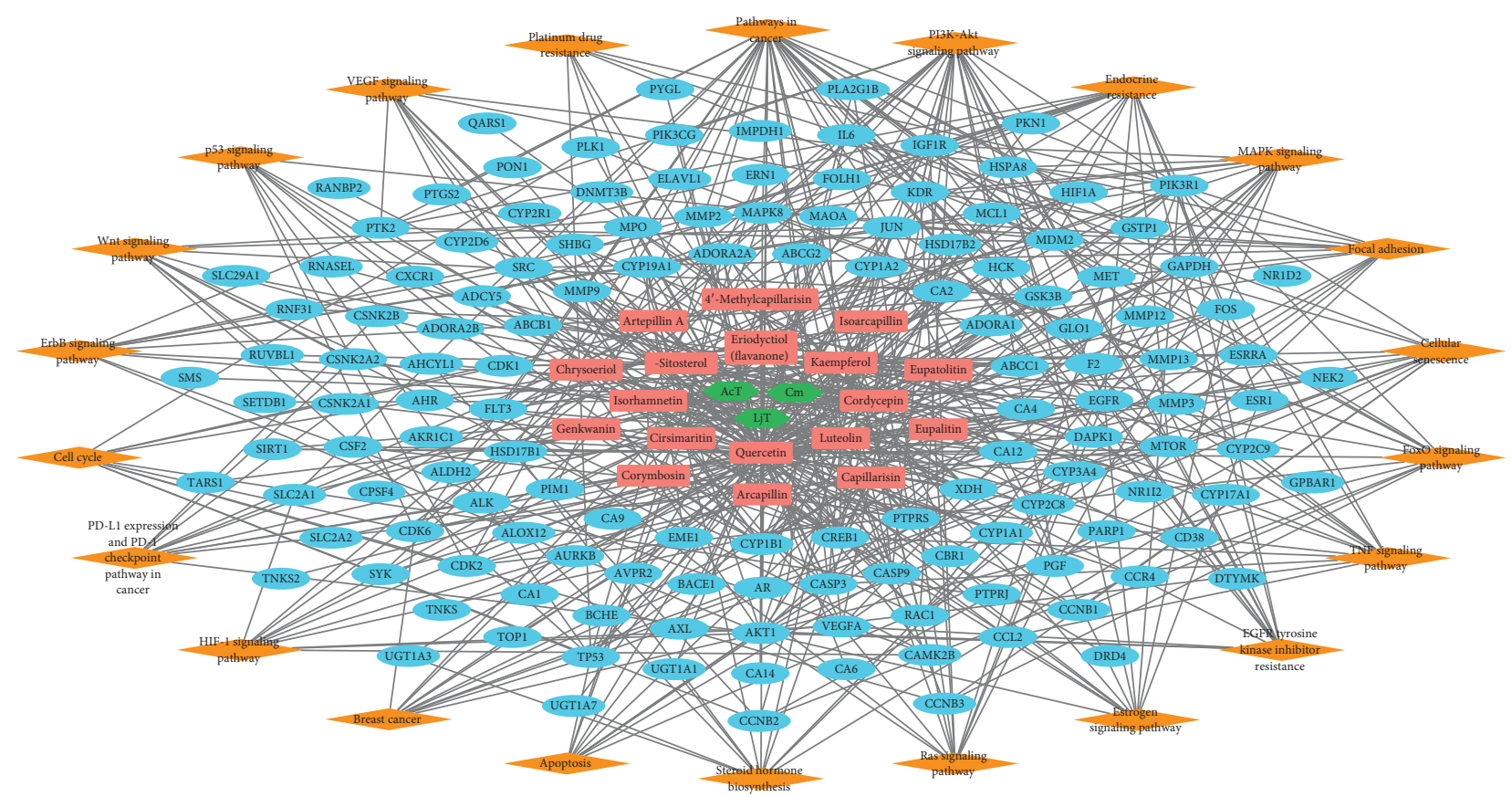

FIGURE 5: Herbal medicine-compound-target-pathway network of FDY003. Green hexagons, herbal medicines; red rectangles, bioactive chemical components; blue ellipses, breast cancer-related targets; orange diamonds, signaling pathways.

components based on extensive network integration. Among the BC-associated targets of FDY003, 38.32\% and $33.65 \%$ of them tended to be coexpressed and physically interacting, respectively (Supplementary Figure S4), suggesting that they have similar biological roles and functions.

Together, the results above suggest that FDY003 exerts the pharmacological activity by targeting diverse BC-associated oncogenic signaling pathways and the modulation of relevant biological functions.

\section{Discussion}

$\mathrm{BC}$ is a common cancer type and ranks as the leading cause of death among women globally [1]. Herbal medicines are attracting considerable attention for potential applications in cancer treatment owing to their high anticancer activities, reduced toxicity, and minimal adverse effects [21]. Based on a network pharmacology analysis, we explored the molecular mechanisms of the therapeutic effects of FDY003 for BC. (i) FDY003 exhibited anticancer effects on human BC cells (Supplementary Figure 1). (ii) Eighteen potentially active compounds (i.e., $4^{\prime}$-methylcapillarisin, arcapillin, artepillin A, capillarisin, chrysoeriol, cirsimaritin, cordycepin, corymbosin, eriodyctiol (flavanone), eupalitin, eupatolitin, genkwanin, isoarcapillin, isorhamnetin, kaempferol, luteolin, quercetin, and $\beta$-sitosterol) present in FDY003 may interact with $140 \mathrm{BC}$-associated therapeutic targets and induce the pharmacological activity of the herbal drug (Figures 1-4). (iii) GO terms for the modulation of cellular processes were significantly enriched for the FDY003 targets, including cell proliferation, cell cycle process, and cell apoptosis (Supplementary Figure 3). In addition, (iv) diverse pathways that play key roles in BC pathology were enriched for the targets that included PI3K-Akt, MAPK, focal adhesion, FoxO, TNF, and estrogen signaling pathways (Figure 5 and Supplementary Figure 3).

The FDY003 constituents have been reported to exert inhibitory effects against BC. AcT inhibited the proliferation but induced the death of BC cells [191]. Cm has been previously demonstrated to reduce the migratory and proliferative capacities of $\mathrm{BC}$ cells and to stimulate apoptosis by promoting caspase activation and Akt inactivation $[29,35,192,193]$. Cm also has immunomodulatory properties that can inhibit the growth of breast tumors [194]. Capillarisin exhibits its anticancer effects by attenuating the invasive and proliferative properties of BC cells [195]. Chrysoeriol treatment has been reported to promote apoptosis and cell cycle arrest and further repress the invasion, proliferation, and migration of BC cells [196, 197]. Cirsimaritin inhibits proliferation and angiogenesis via the downregulation of VEGF, Akt, and extracellular signalregulated kinase (ERK) [198]. Cordycepin is a potent inhibitor of the invasion and proliferation of $\mathrm{BC}$ cells while inducing their apoptosis through the regulation of MAPK and caspase-dependent pathways [199-203]. Cordycepin has also been shown to function as a radiosensitizer that can enhance the efficacy of radiotherapy toward BC cells [204]. Genkwanin modulates the activities of CYP1 enzymes and $\mathrm{PI} 3 \mathrm{~K} / \mathrm{Akt} / \mathrm{mammalian}$ target of rapamycin (mTOR) pathways, thereby suppressing proliferation and inducing apoptosis of BC cells [205-207]. Isorhamnetin exerts the anticancer activity against $\mathrm{BC}$ cells by inhibiting their proliferative and invasive abilities [208-210]. $\beta$-Sitosterol activates key apoptotic pathways, including Fas and caspase signaling pathways, and reduces the viability of BC cells [211-214]. Furthermore, $\beta$-sitosterol has been demonstrated 
to elevate the pharmacological effectiveness of tamoxifen, a selective estrogen receptor modulator that is extensively applied in clinical practice [215]. Kaempferol, luteolin, and quercetin stimulate apoptotic cell death but inhibit cell processes, including proliferation, cell cycle progression, angiogenesis, migration, invasion, metastasis, and cancer stemness; such effects occur via the regulation of important BC-associated pathways such as the Akt, caspase, EGFR, estrogen, HER2, MAPK, insulin-like growth factor (IGF)-1, Notch, and Wnt signaling pathways [216-266]. The three chemical compounds have also been shown to sensitize BC cells to various anticancer drugs, including cisplatin, docetaxel, doxorubicin, lapatinib, paclitaxel, rapamycin, sorafenib, tamoxifen, topotecan, and vincristine [267-286]. For instance, luteolin can synergistically enhance the growth-suppression and apoptosis-inducing activities of the anticancer agent celecoxib against $\mathrm{BC}$ cells by blocking the activation of oncogenic Akt and ERK signaling [271, 272]. The combined treatment of quercetin with kaempferol or luteolin has synergistic antiproliferative effects that are greater than those of either treatment exclusively $[287,288]$. The risk of $\mathrm{BC}$ incidence showed a tendency to be lower in women with higher quercetin intakes [289].

Pharmacologic effects of FDY003 in cancer cells have been previously reported $[24,25]$. FDY003 has been reported to exert its anticancer effects through the regulation of the activities of key mediators of apoptosis and cell cycle progression; these involved Bax, caspase-3, p21, and p53 that induce apoptosis while suppressing the proliferative and survival capacities of cancer cells [24,25]. Treatment with the herbal formula further inhibited tumor growth in xenograft mice bearing human cancer cells [24], suggesting in vivo therapeutic effects against cancer. Contrary to the treatment with irinotecan, a clinically used cytotoxic chemotherapeutic agent [290], body weight loss (a parameter used to evaluate the potential toxicity of drug treatments in animal experiments) did not occur in FDY003-administered xenograft mice [24], suggesting tolerability of the herbal drug as well as its antitumor activity. Future experimental studies should (i) investigate the pharmacological effects of FDY003 in diverse types of cancer, (ii) explore the mechanisms underlying the anticancer activity of the herbal formula such as its immunomodulatory effects, and (iii) evaluate the anticancer effectiveness and safety of FDY003 combined with other widely used therapeutic approaches (i.e., chemotherapy, endocrine therapy, and targeted molecular therapy). Such studies would facilitate the development of safer and more effective herbal medicine-based strategies for BC treatment.

\section{Conclusions}

We explored the systematic mechanisms of FDY003 activity against BC based on a network pharmacology analysis. FDY003 elicited anticancer effects on human BC cells. Eighteen chemical compounds in FDY003 were identified as potentially bioactive compounds that could target $140 \mathrm{BC}$ associated genes/proteins and exhibit therapeutic effects. The FDY003 targets were enriched in GO terms associated

with the modulation of cellular processes, involving cell proliferation, cell cycle progression, and cell apoptosis. Pathway enrichment analysis of the targets further demonstrated that diverse pathways crucial for the BC pathology were significantly enriched with the FDY003 targets, involving the PI3K-Akt, MAPK, focal adhesion, FoxO, TNF, and estrogen signaling pathways. Based on a network perspective, our findings offer in-depth insights into the therapeutic properties of herbal medicines in BC treatment. Future studies should explore the potential efficacy of the herbal formula in other cancer types as well as its potential efficacy and safety profiles in combination with other therapies.

\section{Abbreviations}

AcT:

ADME:

Bax:

C-T:

CI:

$\mathrm{Cm}$ :

CTD:

CYP:

DL:

EGFR:

ErbB:

FoxO:

GO:

$\mathrm{H}-\mathrm{C}$ :

$\mathrm{H}-\mathrm{C}-\mathrm{T}$ :

HIF-1:

HuGE

Navigator:

KEGG:

LjT:

MAPK:

MTT:

NE:

OB:

OMIM:

PD-1:

PD-L1:

PharmGKB:

PI3K:

PPI:

QOL:

SEA:

STITCH:

SysDT:

TCMSP:

TTD:

TNF:

T-P:

VEGF:
Artemisia capillaris Thunberg

Absorption, distribution, metabolism, and excretion

Bcl-2-associated X protein

Compound-target

Contribution index

Cordyceps militaris

The Comparative Toxicogenomics Database

Cytochrome P450

Drug-likeness

Epidermal growth factor receptor

Erythroblastic leukemia viral oncogene

homolog

Forkhead box protein $\mathrm{O}$

Gene ontology

Herb-compound

Herb-target-pathway

Hypoxia-inducible factor 1

Human Genome Epidemiology Navigator

Kyoto Encyclopedia of Genes and Genomes Lonicera japonica Thunberg

Mitogen-activated protein kinase

3-(4,5-Dimethylthiazol-2-yl)-2,5-

diphenyltetrazolium bromide

Network-based efficacy

Oral bioavailability

Online Mendelian Inheritance in Man

Programmed cell death protein 1

Programmed death-ligand 1

Pharmacogenomics Knowledgebase

Phosphoinositide 3-kinase

Protein-protein interaction

Quality of life

Similarity ensemble approach

Search Tool for Interactions of Chemicals

Systematic drug targeting tool

Traditional Chinese medicine systems

pharmacology

Therapeutic Target Database

Tumor necrosis factor

Target-pathway

Vascular endothelial growth factor 
WES

algorithm:

\section{Data Availability}

The data used to support the findings of this study are included within the article.

\section{Conflicts of Interest}

The authors declare that there are no conflicts of interest.

\section{Acknowledgments}

This study was funded by the Fore and Forest Hospital.

\section{Supplementary Materials}

Supplementary Figure S1. Effects of FDY003 on the viability of breast cancer cells. Supplementary Figure S2. Contribution index of active compounds in FDY003. Supplementary Figure S3. Functional enrichment analysis for the breast cancer-associated targets of FDY003. Supplementary Figure S4. Functional interaction analysis for the breast cancerassociated targets of FDY003. Supplementary Table S1. List of the chemical compounds in FDY003. Supplementary Table S2. List of the active chemical compounds in FDY003. Supplementary Table S3. List of the targets of active chemical compounds in FDY003. (Supplementary Materials)

\section{References}

[1] C. E. DeSantis, J. Ma, M. M. Gaudet et al., "Breast cancer statistics, 2019," CA: A Cancer Journal for Clinicians, vol. 69, no. 6, pp. 438-451, 2019.

[2] R. Garcia-Becerra, N. Santos, L. Diaz, and J. Camacho, "Mechanisms of resistance to endocrine therapy in breast cancer: focus on signaling pathways, miRNAs and genetically based resistance," International Journal of Molecular Sciences, vol. 14, no. 1, pp. 108-145, 2020.

[3] P. F. McAuliffe, F. Meric-Bernstam, G. B. Mills, and A. M. Gonzalez-Angulo, "Deciphering the role of PI3K/Akt/ mTOR pathway in breast cancer biology and pathogenesis," Clinical Breast Cancer, vol. 10, no. 3, pp. S59-S65, 2010.

[4] D. Zardavas, J. Baselga, and M. Piccart, "Emerging targeted agents in metastatic breast cancer," Nature Reviews Clinical Oncology, vol. 10, no. 4, pp. 191-210, 2013.

[5] P. den Hollander, M. I. Savage, and P. H. Brown, "Targeted therapy for breast cancer prevention," Frontiers in Oncology, vol. 3, p. 250, 2013.

[6] X. Li, M. T. Lewis, J. Huang et al., "Intrinsic resistance of tumorigenic breast cancer cells to chemotherapy," Journal of the National Cancer Institute, vol. 100, no. 9, pp. 672-679, 2008.

[7] R. Nahta, D. Yu, M. C. Hung, G. N. Hortobagyi, and F. J. Esteva, "Mechanisms of disease: understanding resistance to HER2-targeted therapy in human breast cancer," Nature Clinical Practice Oncology, vol. 3, no. 5, pp. 269-280, 2006.

[8] M. J. Piccart-Gebhart, M. Procter, B. Leyland-Jones et al., "Trastuzumab after adjuvant chemotherapy in HER2- positive breast cancer," The New England Journal of Medicine, vol. 353, no. 16, pp. 1659-1672, 2005.

[9] E. H. Romond, E. A. Perez, J. Bryant et al., "Trastuzumab plus adjuvant chemotherapy for operable HER2-positive breast cancer," The New England Journal of Medicine, vol. 353, no. 16, pp. 1673-1684, 2005.

[10] R. Rouzier, C. M. Perou, W. F. Symmans et al., "Breast cancer molecular subtypes respond differently to preoperative chemotherapy," Clinical Cancer Research, vol. 11, no. 16, pp. 5678-5685, 2005.

[11] M. Abotaleb, P. Kubatka, M. Caprnda et al., "Chemotherapeutic agents for the treatment of metastatic breast cancer: an update," Biomedicine \& Pharmacotherapy, vol. 101, pp. 458-477, 2018.

[12] S. Ali, M. Rasool, H. Chaoudhry et al., "Molecular mechanisms and mode of tamoxifen resistance in breast cancer," Bioinformation, vol. 12, no. 3, pp. 135-139, 2016.

[13] E. A. Ariazi, J. L. Ariazi, F. Cordera, and V. C. Jordan, "Estrogen receptors as therapeutic targets in breast cancer," Current Topics in Medicinal Chemistry, vol. 6, no. 3, pp. 181-202, 2006.

[14] A. Farolfi, E. Melegari, M. Aquilina et al., "Trastuzumabinduced cardiotoxicity in early breast cancer patients: a retrospective study of possible risk and protective factors," Heart, vol. 99, no. 9, pp. 634-639, 2013.

[15] M. Fiuza, "Cardiotoxicity associated with trastuzumab treatment of HER2+ breast cancer," Advances in Therapy, vol. 26, no. 1, pp. S9-S17, 2009.

[16] E. L. Mayer and H. J. Burstein, "Chemotherapy for metastatic breast cancer," Hematology/Oncology Clinics of North America, vol. 21, no. 2, pp. 257-272, 2007.

[17] A. H. Partridge, H. J. Burstein, and E. P. Winer, "Side effects of chemotherapy and combined chemohormonal therapy in women with early-stage breast cancer," JNCI: Journal of the National Cancer Institute, vol. 30, pp. 135-142, 2001.

[18] B. Ramaswamy and C. L. Shapiro, "Osteopenia and osteoporosis in women with breast cancer," Seminars in Oncology, vol. 30, no. 6, pp. 763-775, 2003.

[19] G. R. Zimmermann, J. Lehar, and C. T. Keith, "Multi-target therapeutics: when the whole is greater than the sum of the parts," Drug Discovery Today, vol. 12, no. 1-2, pp. 34-42, 2007.

[20] S. Ohnishi and H. Takeda, "Herbal medicines for the treatment of cancer chemotherapy-induced side effects," Frontiers in Pharmacology, vol. 6, p. 14, 2015.

[21] P. Poornima, J. D. Kumar, Q. Zhao, M. Blunder, and T. Efferth, "Network pharmacology of cancer: from understanding of complex interactomes to the design of multitarget specific therapeutics from nature," Pharmacological Research, vol. 111, pp. 290-302, 2016.

[22] S. Y. Yin, W. C. Wei, F. Y. Jian, and N. S. Yang, "Therapeutic applications of herbal medicines for cancer patients," Evidence-Based Complementary and Alternative Medicine, vol. 2013, Article ID 302426, 15 pages, 2013.

[23] L. Zhu, L. Li, Y. Li, J. Wang, and Q. Wang, "Chinese herbal medicine as an adjunctive therapy for breast cancer: a systematic review and meta-analysis," Evidence-Based Complementary and Alternative Medicine, vol. 2016, Article ID 9469276, 17 pages, 2016.

[24] I.-H. Lee and D.-Y. Lee, "FDY003 inhibits colon cancer in a Colo205 xenograft mouse model by decreasing oxidative stress," Pharmacognosy Magazine, vol. 15, no. 65, p. 675, 2019.

[25] H.-S. Lee, I.-H. Lee, K. Kang et al., "Systems pharmacology study of the anticervical cancer mechanisms of FDY003," Natural Product Communications, vol. 15, no. 12, 2020. 
[26] G. Feng, X. Wang, C. You et al., "Antiproliferative potential of Artemisia capillaris polysaccharide against human nasopharyngeal carcinoma cells," Carbohydrate Polymers, vol. 92, no. 2, pp. 1040-1045, 2013.

[27] M. Hokin-Neaverson and J. W. Jefferson, "Deficient erythrocyte NaK-ATPase activity in different affective states in bipolar affective disorder and normalization by lithium therapy," Neuropsychobiology, vol. 22, no. 1, pp. 18-25, 1989.

[28] E. Jang, S. Y. Kim, N. R. Lee et al., "Evaluation of antitumor activity of Artemisia capillaris extract against hepatocellular carcinoma through the inhibition of IL-6/STAT3 signaling axis," Oncology Reports, vol. 37, no. 1, pp. 526-532, 2017.

[29] C. Y. Jin, G. Y. Kim, and Y. H. Choi, "Induction of apoptosis by aqueous extract of Cordyceps militaris through activation of caspases and inactivation of Akt in human breast cancer MDA-MB-231 Cells," Journal of Microbiology and Biotechnology, vol. 18, no. 12, pp. 1997-2003, 2008.

[30] J. Kim, K. H. Jung, H. H. Yan et al., "Artemisia Capillaris leaves inhibit cell proliferation and induce apoptosis in hepatocellular carcinoma," BMC Complementary Medicine and Therapies, vol. 18, no. 1, p. 147.

[31] K. I. Park, H. Park, A. Nagappan et al., "Polyphenolic compounds from Korean Lonicera japonica Thunb. induces apoptosis via AKT and caspase cascade activation in A549 cells," Oncology Letters, vol. 13, no. 4, pp. 2521-2530, 2017.

[32] Y. K. Rao, S. H. Fang, W. S. Wu, and Y. M. Tzeng, "Constituents isolated from Cordyceps militaris suppress enhanced inflammatory mediator's production and human cancer cell proliferation," Journal of Ethnopharmacology, vol. 131, no. 2, pp. 363-367, 2010.

[33] H. S. Yoo, J. W. Shin, J. H. Cho et al., "Effects of Cordyceps militaris extract on angiogenesis and tumor growth," Acta Pharmacologica Sinica, vol. 25, no. 5, pp. 657-665, 2004.

[34] Q. Zhou, Z. Zhang, L. Song et al., "Cordyceps militaris fraction inhibits the invasion and metastasis of lung cancer cells through the protein kinase B/glycogen synthase kinase 3beta/beta-catenin signaling pathway," Oncology Letters, vol. 16, no. 6, pp. 6930-6939, 2018.

[35] C. Chen, M.-L. Wang, C. Jin et al., "Cordyceps militaris polysaccharide triggers apoptosis and G0/G1 cell arrest in cancer cells," Journal of Asia-Pacific Entomology, vol. 18, no. 3, pp. 433-438, 2015.

[36] C. Hao da and P. G. Xiao, "Network pharmacology: a Rosetta Stone for traditional Chinese medicine," Drug Discovery Today, vol. 75, no. 5, pp. 299-312, 2014.

[37] H. S. Lee, I. H. Lee, S. I. Park, and D. Y. Lee, "Network pharmacology-based investigation of the system-level molecular mechanisms of the hematopoietic activity of samultang, a traditional Korean herbal formula," Evidence-Based Complementary and Alternative Medicine, vol. 2020, Article ID 9048089, , 2020.

[38] W. Y. Lee, C. Y. Lee, Y. S. Kim, and C. E. Kim, "The methodological trends of traditional herbal medicine employing network pharmacology,"Biomolecules, vol. 9, p. 8, 2019.

[39] G. B. Zhang, Q. Y. Li, Q. L. Chen, and S. B. Su, "Network pharmacology: a new approach for Chinese herbal medicine research," Evidence-Based Complementary and Alternative Medicine, vol. 2013, Article ID 621423, 9 pages, 2013.

[40] J. Ru, P. Li, J. Wang et al., "TCMSP: a database of systems pharmacology for drug discovery from herbal medicines," Journal of Cheminformatics, vol. 6, p. 13, 2014.
[41] W. Tao, B. Li, S. Gao et al., "CancerHSP: anticancer herbs database of systems pharmacology," Scientific Reports, vol. 5, p. 11481, 2015.

[42] C. K. Wang and D. J. Craik, "Cyclic peptide oral bioavailability: lessons from the past," Biopolymers, vol. 106, no. 6, pp. 901-909, 2016.

[43] M. N. Garcia, C. Flowers, and J. D. Cook, "The Caco-2 cell culture system can be used as a model to study food iron availability," Journal of Nutrition, vol. 126, no. 1, pp. 251-258, 1996.

[44] Y. Kono, A. Iwasaki, K. Matsuoka, and T. Fujita, "Effect of mechanical agitation on cationic liposome transport across an unstirred water layer in caco-2 cells," Biological and Pharmaceutical Bulletin, vol. 39, no. 8, pp. 1293-1299, 2016.

[45] D. A. Volpe, "Variability in Caco-2 and MDCK cell-based intestinal permeability assays," Journal of Pharmaceutical Sciences, vol. 97, no. 2, pp. 712-725, 2008.

[46] Y. Li, J. Zhang, L. Zhang et al., "Systems pharmacology to decipher the combinational anti-migraine effects of Tianshu formula," Journal of Ethnopharmacology, vol. 174, pp. 45-56, 2015.

[47] J. Zhang, Y. Li, X. Chen, Y. Pan, S. Zhang, and Y. Wang, "Systems pharmacology dissection of multi-scale mechanisms of action for herbal medicines in stroke treatment and prevention," PLoS One, vol. 9, no. 8, Article ID e102506, 2014.

[48] A. Y. Lee, W. Park, T. W. Kang, M. H. Cha, and J. M. Chun, "Network pharmacology-based prediction of active compounds and molecular targets in Yijin-Tang acting on hyperlipidaemia and atherosclerosis," Journal of Ethnopharmacology, vol. 221, pp. 151-159, 2018.

[49] J. Huang, F. Cheung, H. Y. Tan et al., "Identification of the active compounds and significant pathways of yinchenhao decoction based on network pharmacology," Molecular Medicine Reports, vol. 16, no. 4, pp. 4583-4592, 2017.

[50] S. J. Yue, L. T. Xin, Y. C. Fan et al., "Herb pair DangguiHonghua: mechanisms underlying blood stasis syndrome by system pharmacology approach," Scientific Reports, vol. 7, p. 40318, 2017.

[51] D. Szklarczyk, A. Santos, C. von Mering, L. J. Jensen, P. Bork, and M. Kuhn, "STITCH 5: augmenting protein-chemical interaction networks with tissue and affinity data," Nucleic Acids Research, vol. 44, no. D1, pp. D380-D384, 2015.

[52] A. Daina, O. Michielin, and V. Zoete, "SwissTargetPrediction: updated data and new features for efficient prediction of protein targets of small molecules," Nucleic Acids Research, vol. 47, no. W1, pp. W357-W364, 2019.

[53] D. Gfeller, A. Grosdidier, M. Wirth, A. Daina, O. Michielin, and V. Zoete, "SwissTargetPrediction: a web server for target prediction of bioactive small molecules," Nucleic Acids Research, vol. 42, pp. W32-W38, 2014.

[54] X. Wang, Y. Shen, S. Wang et al., "PharmMapper 2017 update: a web server for potential drug target identification with a comprehensive target pharmacophore database," Nucleic Acids Research, vol. 45, no. W1, pp. W356-W360, 2017.

[55] M. J. Keiser, B. L. Roth, B. N. Armbruster, P. Ernsberger, J. J. Irwin, and B. K. Shoichet, "Relating protein pharmacology by ligand chemistry," Nat Biotechnol, vol. 25, no. 2, pp. 197-206, 2007.

[56] H. Yu, J. Chen, X. Xu et al., "A systematic prediction of multiple drug-target interactions from chemical, genomic, 
and pharmacological data," PLoS One, vol. 7, no. 5, Article ID e37608, 2012.

[57] C. Zheng, Z. Guo, C. Huang et al., "Large-scale direct targeting for drug repositioning and discovery," Scientific Reports, vol. 5, p. 11970, 2015.

[58] J. Liu, M. Jiang, Z. Li et al., "A novel systems pharmacology method to investigate molecular mechanisms of scutellaria barbata D. Don for non-small cell lung cancer," Frontiers in Pharmacology, vol. 9, p. 1473, 2018.

[59] X. Su, Y. Li, M. Jiang et al., "Systems pharmacology uncover the mechanism of anti-non-small cell lung cancer for Hedyotis diffusa Willd," Biomedicine \& Pharmacotherapy, vol. 109, pp. 969-984, 2019.

[60] J. Wang, L. Zhang, B. Liu et al., "Systematic investigation of the Erigeron breviscapus mechanism for treating cerebrovascular disease," Journal of Ethnopharmacology, vol. 224, pp. 429-440, 2018.

[61] J. Liu, J. Liu, F. Shen et al., "Systems pharmacology analysis of synergy of TCM: an example using saffron formula," Scientific Reports, vol. 8, no. 1, p. 380, 2018.

[62] J. Liu, J. Zhu, J. Xue et al., "In silico-based screen synergistic drug combinations from herb medicines: a case using Cistanche tubulosa," Scientific Reports, vol. 7, no. 1, p. 16364, 2017.

[63] J. Liu, T. Pei, J. Mu et al., "Systems pharmacology uncovers the multiple mechanisms of xijiao dihuang decoction for the treatment of viral hemorrhagic fever," Evidence-Based Complementary and Alternative Medicine, vol. 2016, Article ID 9025036, 17 pages, 2016.

[64] F. Zhu, B. Han, P. Kumar et al., "Update of TTD: therapeutic target database," Nucleic Acids Research, vol. 38, pp. D787D791, 2009.

[65] M. Safran, I. Dalah, J. Alexander et al., "GeneCards Version 3: the human gene integrator," Database, vol. 2010, p. baq020, 2010.

[66] A. P. Davis, C. J. Grondin, R. J. Johnson et al., "The comparative Toxicogenomics database: update 2019," Nucleic Acids Research, vol. 47, no. D1, pp. D948-D954, 2019.

[67] J. Pinero, A. Bravo, N. Queralt-Rosinach et al., "DisGeNET: a comprehensive platform integrating information on human disease-associated genes and variants," Nucleic Acids Research, vol. 45, no. D1, pp. D833-D839, 2017.

[68] W. Yu, M. Gwinn, M. Clyne, A. Yesupriya, and M. J. Khoury, "A navigator for human genome epidemiology," Nature Genetics, vol. 40, no. 2, pp. 124-125, 2008.

[69] J. S. Amberger, C. A. Bocchini, F. Schiettecatte, A. F. Scott, and A. Hamosh, "OMIM.org: Online Mendelian Inheritance in Man (OMIM(R)), an online catalog of human genes and genetic disorders," Nucleic Acids Research, vol. 43, pp. D789-D798, 2015.

[70] M. Whirl-Carrillo, E. M. McDonagh, J. M. Hebert et al., "Pharmacogenomics knowledge for personalized medicine," Clin Pharmacol Ther, vol. 92, no. 4, pp. 414-417, 2012.

[71] D. S. Wishart, Y. D. Feunang, A. C. Guo et al., "DrugBank 5.0: a major update to the DrugBank database for 2018," Nucleic Acids Research, vol. 46, no. D1, pp. D1074-D1082, 2017.

[72] D. Szklarczyk, A. L. Gable, D. Lyon et al., "STRING v11: protein-protein association networks with increased coverage, supporting functional discovery in genome-wide experimental datasets," Nucleic Acids Research, vol. 47, no. D1, pp. D607-D613, 2019.

[73] P. Shannon, A. Markiel, O. Ozier et al., "Cytoscape: a software environment for integrated models of biomolecular interaction networks," Genome Research, vol. 13, no. 11, pp. 2498-2504, 2003.

[74] A. L. Barabasi and Z. N. Oltvai, "Network biology: understanding the cell's functional organization," Nature Reviews Genetics, vol. 5, no. 2, pp. 101-113, 2004.

[75] U. Raudvere, L. Kolberg, I. Kuzmin et al., "g:Profiler: a web server for functional enrichment analysis and conversions of gene lists (2019 update)," Nucleic Acids Research, vol. 47pp. W191-W198, W1, 2019.

[76] M. Kanehisa and S. Goto, "KEGG: kyoto encyclopedia of genes and genomes," Nucleic Acids Research, vol. 28, no. 1, pp. 27-30, 2000.

[77] D. Y. Cho, Y. A. Kim, and T. M. Przytycka, "Chapter 5: network biology approach to complex diseases," PLoS Computational Biology, vol. 8, no. 12, Article ID e1002820, 2012.

[78] H. Jeong, S. P. Mason, A. L. Barabasi, and Z. N. Oltvai, "Lethality and centrality in protein networks," Nature, vol. 411, no. 6833, pp. 41-42, 2001.

[79] J. Zhu, X. Yi, Y. Zhang, Z. Pan, L. Zhong, and P. Huang, "Systems pharmacology-based approach to comparatively study the independent and synergistic mechanisms of danhong injection and naoxintong capsule in ischemic stroke treatment," Evidence-Based Complementary and Alternative Medicine, vol. 2019, Article ID 1056708, 17 pages, 2010.

[80] J. Zhong, Z. Liu, X. Zhou, and J. Xu, "Synergic anti-pruritus mechanisms of action for the radix sophorae flavescentis and fructus cnidii herbal pair," Molecules, vol. 229 pages, 2017.

[81] L. D. Miller, J. Smeds, J. George et al., "An expression signature for p53 status in human breast cancer predicts mutation status, transcriptional effects, and patient survival," Proceedings of the National Academy of Sciences of the United States of America, vol. 102, no. 38, pp. 13550-13555, 2005.

[82] P. Yang, C. W. Du, M. Kwan, S. X. Liang, and G. J. Zhang, "The impact of p53 in predicting clinical outcome of breast cancer patients with visceral metastasis," Scientific Reports, vol. 3, p. 2246, 2020

[83] M. D. Wellenstein, S. B. Coffelt, D. E. M. Duits et al., "Loss of p53 triggers WNT-dependent systemic inflammation to drive breast cancer metastasis," Nature, vol. 572, no. 7770, pp. 538-542, 2019.

[84] L. Y. Lim, N. Vidnovic, L. W. Ellisen, and C. O. Leong, "Mutant p53 mediates survival of breast cancer cells," British Journal of Cancer, vol. 101, no. 9, pp. 1606-1612, 2009.

[85] M. Lacroix, R. A. Toillon, and G. Leclercq, "p53 and breast cancer, an update," Endocrine-Related Cancer, vol. 13, no. 2, pp. 293-325, 2006.

[86] H. Yamashita, T. Toyama, M. Nishio et al., "p53 protein accumulation predicts resistance to endocrine therapy and decreased post-relapse survival in metastatic breast cancer," Breast Cancer Research, vol. 8, no. 4, p. R48, 2006.

[87] D. Walerych, M. Napoli, L. Collavin, and G. Del Sal, “The rebel angel: mutant p53 as the driving oncogene in breast cancer," Carcinogenesis, vol. 33, no. 11, pp. 2007-2017, 2012.

[88] N. Turner, E. Moretti, O. Siclari et al., "Targeting triple negative breast cancer: is p53 the answer?" Cancer Treatment Reviews, vol. 39, no. 5, pp. 541-550, 2013.

[89] B. Na, X. Yu, T. Withers et al., "Therapeutic targeting of BRCA1 and TP53 mutant breast cancer through mutant p53 reactivation," NPJ Breast Cancer, vol. 5, p. 14, 2019.

[90] E. L. Mayer and I. E. Krop, "Advances in targeting SRC in the treatment of breast cancer and other solid malignancies," 
Clinical Cancer Research, vol. 16, no. 14, pp. 3526-3532, 2010.

[91] S. Hiscox, L. Morgan, T. P. Green, D. Barrow, J. Gee, and R. I. Nicholson, "Elevated Src activity promotes cellular invasion and motility in tamoxifen resistant breast cancer cells," Breast Cancer Research and Treatment, vol. 97, no. 3, pp. 263-274, 2006.

[92] X. H. Zhang, Q. Wang, W. Gerald et al., "Latent bone metastasis in breast cancer tied to Src-dependent survival signals," Cancer Cell, vol. 16, no. 1, pp. 67-78, 2009.

[93] F. Saad and A. Lipton, "SRC kinase inhibition: targeting bone metastases and tumor growth in prostate and breast cancer," Cancer Treatment Reviews, vol. 36, no. 2, pp. 177-184, 2010.

[94] H. Jallal, M. L. Valentino, G. Chen, F. Boschelli, S. Ali, and S. A. Rabbani, "A Src/Abl kinase inhibitor, SKI-606, blocks breast cancer invasion, growth, and metastasis in vitro and in vivo," Cancer Research, vol. 67, no. 4, pp. 1580-1588, 2007.

[95] B. Elsberger, R. Fullerton, S. Zino et al., "Breast cancer patients' clinical outcome measures are associated with Src kinase family member expression," British Journal of Cancer, vol. 103, no. 6, pp. 899-909, 2010.

[96] B. S. Verbeek, T. M. Vroom, S. S. Adriaansen-Slot et al., "cSrc protein expression is increased in human breast cancer. An immunohistochemical and biochemical analysis," The Journal of Pathology, vol. 180, no. 4, pp. 383-388, 1996.

[97] Y. Yang, M. Li, and Y. Li, "High expression of PIK3R1 (p85 $\alpha$ ) correlates with poor survival in patients with metastatic breast cancer," Int Journal of Clinical and Experimental Pathology, vol. 9, no. 12, pp. 12797-12806.

[98] H. J. Burstein, Y. H. Chen, L. M. Parker et al., "VEGF as a marker for outcome among advanced breast cancer patients receiving anti-VEGF therapy with bevacizumab and vinorelbine chemotherapy," Clinical Cancer Research, vol. 14, no. 23, pp. 7871-7877, 2008.

[99] Y. Liang, R. A. Brekken, and S. M. Hyder, "Vascular endothelial growth factor induces proliferation of breast cancer cells and inhibits the anti-proliferative activity of anti-hormones," Endocrine-Related Cancer, vol. 13, no. 3, pp. 905-919, 2006.

[100] M. Luo, L. Hou, J. Li et al., "VEGF/NRP-1axis promotes progression of breast cancer via enhancement of epithelialmesenchymal transition and activation of NF-kappaB and beta-catenin," Cancer Letters, vol. 373, no. 1, pp. 1-11, 2016.

[101] M. Perrot-Applanat and M. Di Benedetto, "Autocrine functions of VEGF in breast tumor cells: adhesion, survival, migration and invasion," Cell Adhesion \& Migration, vol. 6, no. 6, pp. 547-553, 2012.

[102] S. B. Vestey, C. Sen, C. J. Calder, C. M. Perks, M. Pignatelli, and Z. E. Winters, "Activated Akt expression in breast cancer: correlation with p53, Hdm2 and patient outcome," European Journal of Cancer, vol. 41, no. 7, pp. 1017-1025, 2005.

[103] G. Perez-Tenorio, O. Stal, and G. Southeast Sweden Breast Cancer, "Activation of AKT/PKB in breast cancer predicts a worse outcome among endocrine treated patients," British Journal of Cancer, vol. 86, no. 4, pp. 540-545, 2002.

[104] T. Kirkegaard, C. J. Witton, L. M. McGlynn et al., “AKT activation predicts outcome in breast cancer patients treated with tamoxifen," The Journal of Pathology, vol. 207, no. 2, pp. 139-146, 2005.

[105] P. Grell, P. Fabian, M. Khoylou et al., "Akt expression and compartmentalization in prediction of clinical outcome in HER2-positive metastatic breast cancer patients treated with trastuzumab," International Journal of Oncology, vol. 41, no. 4, pp. 1204-1212, 2012.
[106] E. Tokunaga, A. Kataoka, Y. Kimura et al., "The association between Akt activation and resistance to hormone therapy in metastatic breast cancer," European Journal of Cancer, vol. 42, no. 5, pp. 629-635, 2006.

[107] M. M. Vleugel, A. E. Greijer, R. Bos, E. van der Wall, and P. J. van Diest, "c-Jun activation is associated with proliferation and angiogenesis in invasive breast cancer," Human Pathology, vol. 37, no. 6, pp. 668-674, 2006.

[108] X. Jiao, S. Katiyar, N. E. Willmarth et al., "c-Jun induces mammary epithelial cellular invasion and breast cancer stem cell expansion," Journal of Biological Chemistry, vol. 285, no. 11, pp. 8218-8226, 2010.

[109] Y. Zhang, X. Pu, M. Shi et al., "c-Jun, a crucial molecule in metastasis of breast cancer and potential target for biotherapy," Oncology Reports, vol. 18, no. 5, pp. 1207-1212, 2007.

[110] Y. Zhang, X. Pu, M. Shi et al., "Critical role of c-Jun overexpression in liver metastasis of human breast cancer xenograft model," BMC Cancer, vol. 7, p. 145, 2007.

[111] A. E. Teschendorff, L. Li, and Z. Yang, "Denoising perturbation signatures reveal an actionable AKT-signaling gene module underlying a poor clinical outcome in endocrinetreated ER+ breast cancer," Genome Biology, vol. 16, p. 61, 2015.

[112] N. M. Davis, M. Sokolosky, K. Stadelman et al., "Deregulation of the EGFR/PI3K/PTEN/Akt/mTORC1 pathway in breast cancer: possibilities for therapeutic intervention," Oncotarget, vol. 5, no. 13, pp. 4603-4650, 2014.

[113] H. Nogi, T. Kobayashi, M. Suzuki et al., "EGFR as paradoxical predictor of chemosensitivity and outcome among triple-negative breast cancer," Oncology Reports, vol. 21, no. 2, pp. 413-417, 2009.

[114] D. Liu, J. He, Z. Yuan et al., "EGFR expression correlates with decreased disease-free survival in triple-negative breast cancer: a retrospective analysis based on a tissue microarray," Medical Oncology, vol. 29, no. 2, pp. 401-405, 2012.

[115] S. O. Lim, C. W. Li, W. Xia et al., "EGFR signaling enhances aerobic glycolysis in triple-negative breast cancer cells to promote tumor growth and immune escape," Cancer Research, vol. 76, no. 5, pp. 1284-1296, 2016.

[116] K. L. Mueller, K. Powell, J. M. Madden, S. T. Eblen, and J. L. Boerner, "EGFR tyrosine 845 phosphorylation-dependent proliferation and transformation of breast cancer cells require activation of p38 MAPK," Translational Oncology, vol. 5, no. 5, pp. 327-334, 2012.

[117] L. Dihge, P. O. Bendahl, D. Grabau et al., "Epidermal growth factor receptor (EGFR) and the estrogen receptor modulator amplified in breast cancer (AIB1) for predicting clinical outcome after adjuvant tamoxifen in breast cancer," Breast Cancer Research and Treatment, vol. 109, no. 2, pp. 255-262, 2008.

[118] H. S. Park, M. H. Jang, E. J. Kim et al., "High EGFR gene copy number predicts poor outcome in triple-negative breast cancer," Modern Pathology, vol. 27, no. 9, pp. 1212-1222.

[119] S. E. Ghayad and P. A. Cohen, "Inhibitors of the PI3K/Akt/ mTOR pathway: new hope for breast cancer patients," Recent Patents on Anti-Cancer Drug Discovery, vol. 5, no. 1, pp. 29-57.

[120] S. Langer, C. F. Singer, G. Hudelist et al., "Jun and Fos family protein expression in human breast cancer: correlation of protein expression and clinicopathological parameters," European Journal of Gynaecological Oncology, vol. 27, no. 4, pp. 345-352, 2014. 
[121] X. L. Yan, C. J. Fu, L. Chen et al., "Mesenchymal stem cells from primary breast cancer tissue promote cancer proliferation and enhance mammosphere formation partially via EGF/EGFR/Akt pathway," Breast Cancer Research and Treatment, vol. 132, no. 1, pp. 153-164, 2012.

[122] B. S. Verbeek, S. S. Adriaansen-Slot, T. M. Vroom, T. Beckers, and G. Rijksen, "Overexpression of EGFR and c-erbB2 causes enhanced cell migration in human breast cancer cells and NIH3T3 fibroblasts," FEBS Letters, vol. 425, no. 1, pp. 145-150, 1998.

[123] C. A. Castaneda, H. Cortes-Funes, H. L. Gomez, and E. M. Ciruelos, "The phosphatidyl inositol 3-kinase/AKT signaling pathway in breast cancer," Cancer and Metastasis Reviews, vol. 29, no. 4, pp. 751-759, 2010.

[124] G. Kallergi, S. Agelaki, A. Kalykaki, C. Stournaras, D. Mavroudis, and V. Georgoulias, "Phosphorylated EGFR and PI3K/Akt signaling kinases are expressed in circulating tumor cells of breast cancer patients," Breast Cancer Research, vol. 10, no. 5, p. R80.

[125] E. Paplomata and R. O'Regan, “The PI3K/AKT/mTOR pathway in breast cancer: targets, trials and biomarkers," Therapeutic Advances in Medical Oncology, vol. 6, no. 4, pp. 154-166, 2008.

[126] K. S. Saini, S. Loi, E. de Azambuja et al., "Targeting the PI3K/ AKT/mTOR and Raf/MEK/ERK pathways in the treatment of breast cancer," Cancer Treatment Reviews, vol. 39, no. 8, pp. 935-946, 2013.

[127] J. Briggs, S. Chamboredon, M. Castellazzi, J. A. Kerry, and T. J. Bos, "Transcriptional upregulation of SPARC, in response to c-Jun overexpression, contributes to increased motility and invasion of MCF7 breast cancer cells," Oncogene, vol. 21, no. 46, pp. 7077-7091, 2002.

[128] N. J. Jordan, J. M. Gee, D. Barrow, A. E. Wakeling, and R. I. Nicholson, "Increased constitutive activity of PKB/Akt in tamoxifen resistant breast cancer MCF-7 cells," Breast Cancer Research and Treatment, vol. 87, no. 2, pp. 167-180, 2004.

[129] J. M. Albert, K. W. Kim, C. Cao, and B. Lu, "Targeting the Akt/mammalian target of rapamycin pathway for radiosensitization of breast cancer," Molecular Cancer Therapeutics, vol. 5, no. 5, pp. 1183-1189, 2006.

[130] K. Liang, W. Jin, C. Knuefermann et al., "Targeting the phosphatidylinositol 3-kinase/Akt pathway for enhancing breast cancer cells to radiotherapy," Molecular Cancer Therapeutics, vol. 2, no. 4, pp. 353-360, 2003.

[131] J. J. Lee, K. Loh, and Y. S. Yap, "PI3K/Akt/mTOR inhibitors in breast cancer," Cancer Biology \& Medicine, vol. 12, no. 4, pp. 342-354, 2015.

[132] M. Rodriguez and D. A. Potter, "CYP1A1 regulates breast cancer proliferation and survival," Molecular Cancer Research, vol. 11, no. 7, pp. 780-792, 2013.

[133] Y. Huang, A. Trentham-Dietz, M. Garcia-Closas et al., "Association of CYP1B1 haplotypes and breast cancer risk in Caucasian women," Cancer Epidemiology, Biomarkers \& Prevention, vol. 18, no. 4, pp. 1321-1323, 2009.

[134] C. S. Huang, H. D. Chern, K. J. Chang, C. W. Cheng, S. M. Hsu, and C. Y. Shen, "Breast cancer risk associated with genotype polymorphism of the estrogen-metabolizing genes CYP17, CYP1A1, and COMT: a multigenic study on cancer susceptibility," Cancer Research, vol. 59, no. 19, pp. 48704875, 1999.

[135] R. Mitra, Z. Guo, M. Milani et al., "CYP3A4 mediates growth of estrogen receptor-positive breast cancer cells in part by inducing nuclear translocation of phospho-Stat3 through biosynthesis of (+/-)-14,15-epoxyeicosatrienoic acid (EET)," Journal of Biological Chemistry, vol. 286, no. 20, pp. 17543-17559, 2011.

[136] N. Napoli, D. T. Villareal, S. Mumm et al., "Effect of CYP1A1 gene polymorphisms on estrogen metabolism and bone density," Journal of Bone and Mineral Research, vol. 20, no. 2, pp. 232-239, 2005.

[137] A. M. Yu, K. Fukamachi, K. W. Krausz, C. Cheung, and F. J. Gonzalez, "Potential role for human cytochrome P450 3A4 in estradiol homeostasis," Endocrinology, vol. 146, no. 7, pp. 2911-2919, 2005.

[138] Z. N. Cheng, Y. Shu, Z. Q. Liu, L. S. Wang, D. S. Ou-Yang, and H. H. Zhou, "Role of cytochrome P450 in estradiol metabolism in vitro," Acta Pharmacologica Sinica, vol. 22, no. 2, pp. 148-154, 2001.

[139] E. Taioli, H. L. Bradlow, S. V. Garbers et al., "Role of estradiol metabolism and CYP1A1 polymorphisms in breast cancer risk," Cancer Detection and Prevention, vol. 23, no. 3, pp. 232-237, 1999.

[140] X. Zhou, G. Qiao, X. Wang et al., "CYP1A1 genetic polymorphism is a promising predictor to improve chemotherapy effects in patients with metastatic breast cancer treated with docetaxel plus thiotepa vs. docetaxel plus capecitabine," Cancer Chemotherapy and Pharmacology, vol. 81, no. 2, pp. 365-372, 2018.

[141] K. Sakurai, K. Enomoto, S. Matsuo, S. Amano, and M. Shiono, "CYP3A4 expression to predict treatment response to docetaxel for metastasis and recurrence of primary breast cancer," Surgery Today, vol. 41, no. 5, pp. 674-679, 2011.

[142] S. Izadi, A. Nikkhoo, M. Hojjat-Farsangi et al., "CDK1 in breast cancer: implications for theranostic potential," AntiCancer Agents in Medicinal Chemistry, vol. 20, no. 7, pp. 758-767, 2020.

[143] Q. Xia, Y. Cai, R. Peng, G. Wu, Y. Shi, and W. Jiang, "The CDK1 inhibitor RO3306 improves the response of BRCApro fi cient breast cancer cells to PARP inhibition," International Journal of Oncology, vol. 44, no. 3, pp. 735-744, 2014.

[144] S. J. Kim, N. Masuda, F. Tsukamoto et al., "The cell cycle profiling-risk score based on CDK1 and 2 predicts early recurrence in node-negative, hormone receptor-positive breast cancer treated with endocrine therapy," Cancer Letters, vol. 355, no. 2, pp. 217-223, 2014.

[145] S. J. Kim, S. Nakayama, Y. Miyoshi et al., "Determination of the specific activity of CDK1 and CDK2 as a novel prognostic indicator for early breast cancer," Annals of Oncology, vol. 19, no. 1, pp. 68-72, 2008.

[146] S. Nakayama, Y. Torikoshi, T. Takahashi et al., "Prediction of paclitaxel sensitivity by CDK1 and CDK2 activity in human breast cancer cells," Breast Cancer Research, vol. 11, no. 1, p. R12, 2009.

[147] J. Kang, C. M. Sergio, R. L. Sutherland, and E. A. Musgrove, "Targeting cyclin-dependent kinase 1 (CDK1) but not CDK4/6 or CDK2 is selectively lethal to MYC-dependent human breast cancer cells," BMC Cancer, vol. 14, p. 32, 2014.

[148] S. J. Yue, J. Liu, W. W. Feng et al., "System pharmacologybased dissection of the synergistic mechanism of huangqi and huanglian for diabetes mellitus," Frontiers in Pharmacology, vol. 8, p. 694, 2017.

[149] W. Kolch, M. Halasz, M. Granovskaya, and B. N. Kholodenko, "The dynamic control of signal transduction networks in cancer cells," Nature Reviews Cancer, vol. 15, no. 9, pp. 515-527, 2015. 
[150] K. M. Hardy, B. W. Booth, M. J. Hendrix, D. S. Salomon, and L. Strizzi, "ErbB/EGF signaling and EMT in mammary development and breast cancer," Journal of Mammary Gland Biology and Neoplasia, vol. 15, no. 2, pp. 191-199, 2010.

[151] M. Luo and J. L. Guan, "Focal adhesion kinase: a prominent determinant in breast cancer initiation, progression and metastasis," Cancer Letters, vol. 289, no. 2, pp. 127-139, 2010.

[152] M. Bullock, "FOXO factors and breast cancer: outfoxing endocrine resistance," Endocrine-Related Cancer, vol. 23, no. 2, pp. R113-R130, 2016.

[153] M. Farhan, H. Wang, U. Gaur, P. J. Little, J. Xu, and W. Zheng, "FOXO signaling pathways as therapeutic targets in cancer," International Journal of Biological Sciences, vol. 13, no. 7, pp. 815-827, 2017.

[154] T. Li and J. A. Sparano, "Inhibiting Ras signaling in the therapy of breast cancer," Clinical Breast Cancer, vol. 3, no. 6, pp. 405-416, 2003.

[155] P. D. Angelini, M. F. Zacarias Fluck, K. Pedersen et al., "Constitutive HER2 signaling promotes breast cancer metastasis through cellular senescence," Cancer Res, vol. 73, no. 1, pp. 450-458, 2013.

[156] P. Lipponen, "Apoptosis in breast cancer: relationship with other pathological parameters," Endocrine-Related Cancer, vol. 6, no. 1, pp. 13-16, 1999.

[157] R. Pare, T. Yang, J. S. Shin, and C. S. Lee, "The significance of the senescence pathway in breast cancer progression," Journal of Clinical Pathology, vol. 66, no. 6, pp. 491-495, 2013.

[158] M. Parton, M. Dowsett, and I. Smith, "Studies of apoptosis in breast cancer," BMJ, vol. 322, no. 7301, pp. 1528-1532, 2001.

[159] P. G. Roy and A. M. Thompson, "Cyclin D1 and breast cancer," Breast, vol. 15, no. 6, pp. 718-727, 1998.

[160] R. L. Sutherland and E. A. Musgrove, "Cyclins and breast cancer," Journal of Mammary Gland Biology and Neoplasia, vol. 9, no. 1, pp. 95-104, 2004.

[161] J. E. Goldberg and K. L. Schwertfeger, "Proinflammatory cytokines in breast cancer: mechanisms of action and potential targets for therapeutics," Current Cancer Drug Targets, vol. 11, no. 9, pp. 1133-1146, 2010.

[162] M. F. Mercogliano, S. Bruni, P. V. Elizalde, and R. Schillaci, "Tumor necrosis factor alpha blockade: an opportunity to tackle breast cancer," Frontiers in Oncology, vol. 10, p. 584, 2020.

[163] S. Hayashi, T. Niwa, and Y. Yamaguchi, "Estrogen signaling pathway and its imaging in human breast cancer," Cancer Sciences, vol. 100, no. 10, pp. 1773-1778, 2009.

[164] R. Nahta and R. M. O’Regan, “Therapeutic implications of estrogen receptor signaling in HER2-positive breast cancers," Breast Cancer Research and Treatment, vol. 135, no. 1, pp. 39-48, 2012.

[165] J. M. Renoir, V. Marsaud, and G. Lazennec, "Estrogen receptor signaling as a target for novel breast cancer therapeutics," Biochemical Pharmacology, vol. 85, no. 4, pp. 449-465, 2013.

[166] S. Saha Roy and R. K. Vadlamudi, "Role of estrogen receptor signaling in breast cancer metastasis," International Journal of Breast Cancer, vol. 2012, Article ID 654698, 2012.

[167] T. Saha, S. Makar, R. Swetha, G. Gutti, and S. K. Singh, "Estrogen signaling: an emanating therapeutic target for breast cancer treatment," European Journal of Medicinal Chemistry, vol. 177, pp. 116-143, 2019.

[168] G. P. Andrieu, J. S. Shafran, C. L. Smith et al., "BET protein targeting suppresses the PD-1/PD-L1 pathway in triple- negative breast cancer and elicits anti-tumor immune response," Cancer Letters, vol. 465, pp. 45-58, 2019.

[169] S. Chretien, I. Zerdes, J. Bergh, A. Matikas, and T. Foukakis, "Beyond PD-1/PD-L1 inhibition: what the future holds for breast cancer immunotherapy," Cancers (Basel), vol. 115 pages, 2019.

[170] Y. Guo, P. Yu, Z. Liu et al., "Prognostic and clinicopathological value of programmed death ligand-1 in breast cancer: a meta-analysis," PLoS One, vol. 11, no. 5, Article ID e0156323, 2016.

[171] X. Jing, S. Shao, Y. Zhang et al., "BRD4 inhibition suppresses PD-L1 expression in triple-negative breast cancer," Experimental Cell Research, vol. 392, no. 2, Article ID 112034, 2010.

[172] S. Muenst, A. R. Schaerli, F. Gao et al., "Expression of programmed death ligand 1 (PD-L1) is associated with poor prognosis in human breast cancer," Breast Cancer Research and Treatment, vol. 146, no. 1, pp. 15-24, 2014.

[173] G. B. Jang, J. Y. Kim, S. D. Cho et al., "Blockade of Wnt/betacatenin signaling suppresses breast cancer metastasis by inhibiting CSC-like phenotype," Scientific Reports, vol. 5, p. 12465, 2015.

[174] L. P. Schwab, D. L. Peacock, D. Majumdar et al., "Hypoxiainducible factor 1alpha promotes primary tumor growth and tumor-initiating cell activity in breast cancer," Breast Cancer Research, vol. 14, no. 1, p. R6, 2012.

[175] G. L. Semenza, "Hypoxia-inducible factors: coupling glucose metabolism and redox regulation with induction of the breast cancer stem cell phenotype," The EMBO Journal, vol. 36, no. 3, pp. 252-259, 2017.

[176] D. M. Gilkes and G. L. Semenza, "Role of hypoxia-inducible factors in breast cancer metastasis," Future Oncology, vol. 9, no. 11, pp. 1623-1636, 2013.

[177] R. Lamb, M. P. Ablett, K. Spence, G. Landberg, A. H. Sims, and R. B. Clarke, "Wnt pathway activity in breast cancer subtypes and stem-like cells," PLoS One, vol. 8, no. 7, Article ID e67811, 2013

[178] N. Dey, B. G. Barwick, C. S. Moreno et al., "Wnt signaling in triple negative breast cancer is associated with metastasis," BMC Cancer, vol. 13, p. 537, 2013.

[179] S. G. Pohl, N. Brook, M. Agostino, F. Arfuso, A. P. Kumar, and A. Dharmarajan, "Wnt signaling in triple-negative breast cancer," Oncogenesis, vol. 6, no. 4, p. e310, 2017.

[180] J. R. Prosperi and K. H. Goss, "A Wnt-ow of opportunity: targeting the Wnt/beta-catenin pathway in breast cancer," Current Cancer Drug Targets, vol. 11, no. 9, pp. 1074-1088, 2010.

[181] M. Gasco, S. Shami, and T. Crook, "The p53 pathway in breast cancer," Breast Cancer Research, vol. 4, no. 2, pp. 70-76, 2002.

[182] A. M. Mercurio, E. A. Lipscomb, and R. E. Bachelder, "Nonangiogenic functions of VEGF in breast cancer," Journal of Mammary Gland Biology and Neoplasia, vol. 10, no. 4, pp. 283-290, 2005.

[183] E. A. Musgrove and R. L. Sutherland, "Biological determinants of endocrine resistance in breast cancer," Nature Reviews Cancer, vol. 9, no. 9, pp. 631-643, 2009.

[184] A. S. Clark, K. West, S. Streicher, and P. A. Dennis, "Constitutive and inducible Akt activity promotes resistance to chemotherapy, trastuzumab, or tamoxifen in breast cancer cells," Molecular Cancer Therapeutics, vol. 1, no. 9, pp. 707-717, 2002.

[185] R. Clarke, J. J. Tyson, and J. M. Dixon, "Endocrine resistance in breast cancer--An overview and update," Molecular and Cellular Endocrinology, vol. 418, no. 3, pp. 220-234, 2015. 
[186] N. Eckstein, "Platinum resistance in breast and ovarian cancer cell lines," Journal of Experimental \& Clinical Cancer Research, vol. 30, p. 91, 2011.

[187] M. P. Decatris, S. Sundar, and K. J. O'Byrne, "Platinumbased chemotherapy in metastatic breast cancer: current status," Cancer Treatment Reviews, vol. 30, no. 1, pp. 53-81, 2004.

[188] P. R. Pohlmann, I. A. Mayer, and R. Mernaugh, "Resistance to trastuzumab in breast cancer," Clinical Cancer Research, vol. 15, no. 24, pp. 7479-7491, 2009.

[189] C. K. Osborne and R. Schiff, "Mechanisms of endocrine resistance in breast cancer," Annual Review of Medicine, vol. 62, pp. 233-247, 2011.

[190] J. Montojo, K. Zuberi, H. Rodriguez, G. D. Bader, and Q. Morris, "GeneMANIA: fast gene network construction and function prediction for Cytoscape," F1000Research, vol. 3, p. 153, 2014.

[191] J.-H. Kim, D.-H. Kim, J.-H. You et al., "Comparison of cytotoxin and immune activities between natural and tissue cultured plant in Artemisia capillaris thunb," Korean Journal of Medicinal Crop Science, vol. 13, no. 4, pp. 154-160, 2005.

[192] J. Song, Y. Wang, M. Teng et al., "Cordyceps militaris induces tumor cell death via the caspasedependent mitochondrial pathway in HepG2 and MCF7 cells," Molecular Medicine Reports, vol. 13, no. 6, pp. 5132-5140, 2016.

[193] H. C. Wu, S. T. Chen, J. C. Chang et al., "Radical scavenging and antiproliferative effects of cordycepin-rich ethanol extract from Brown rice-cultivated Cordyceps militaris (ascomycetes) mycelium on breast cancer cell lines," International Journal of Medicinal Mushrooms, vol. 21, no. 7, pp. 657-669, 2019.

[194] M. H. Jeong, C. M. Lee, S. W. Lee et al., "Cordycepinenriched Cordyceps militaris induces immunomodulation and tumor growth delay in mouse-derived breast cancer," Oncology Reports, vol. 30, no. 4, pp. 1996-2002, 2013.

[195] S. O. Lee, Y. J. Jeong, M. Kim, C. H. Kim, and I. S. Lee, "Suppression of PMA-induced tumor cell invasion by capillarisin via the inhibition of NF-kappaB-dependent MMP-9 expression," Biochemical and Biophysical Research Communications, vol. 366, no. 4, pp. 1019-1024, 2008.

[196] K. Amrutha, P. Nanjan, S. K. Shaji et al., "Discovery of lesser known flavones as inhibitors of NF-kappaB signaling in MDA-MB-231 breast cancer cells-a SAR study," Bioorganic \& Medicinal Chemistry Letters, vol. 24, no. 19, pp. 47354742, 2014.

[197] H. Takemura, H. Uchiyama, T. Ohura et al., "A methoxyflavonoid, chrysoeriol, selectively inhibits the formation of a carcinogenic estrogen metabolite in MCF-7 breast cancer cells," The Journal of Steroid Biochemistry and Molecular Biology, vol. 118, no. 1-2, pp. 70-76, 2009.

[198] J. Yeon Park, H. Young Kim, T. Shibamoto et al., "Beneficial effects of a medicinal herb, Cirsium japonicum var. maackii, extract and its major component, cirsimaritin on breast cancer metastasis in MDA-MB-231 breast cancer cells," Bioorganic \& Medicinal Chemistry Letters, vol. 27, no. 17, pp. 3968-3973, 2017.

[199] E. M. Noh, H. J. Youn, S. H. Jung et al., "Cordycepin inhibits TPA-induced matrix metalloproteinase- 9 expression by suppressing the MAPK/AP-1 pathway in MCF-7 human breast cancer cells," International Journal of Molecular Medicine, vol. 25, no. 2, pp. 255-260, 2010.

[200] D. Wang, Y. Zhang, J. Lu et al., "Cordycepin, a natural antineoplastic agent, induces apoptosis of breast cancer cells via caspase-dependent pathways," Natural Product Communications, vol. 11, no. 1, pp. 63-68, 2016.

[201] S. Choi, M. H. Lim, K. M. Kim, B. H. Jeon, W. O. Song, and T. W. Kim, "Cordycepin-induced apoptosis and autophagy in breast cancer cells are independent of the estrogen receptor," Toxicology and Applied Pharmacology, vol. 257, no. 2, pp. 165-173, 2011.

[202] D. Lee, W. Y. Lee, K. Jung et al., "The inhibitory effect of cordycepin on the proliferation of MCF-7 breast cancer cells, and its mechanism: an investigation using network pharmacology-based analysis," Biomolecules, vol. 9, no. 9, 2019.

[203] H. J. Lee, P. Burger, M. Vogel, K. Friese, and A. Bruning, "The nucleoside antagonist cordycepin causes DNA double strand breaks in breast cancer cells," Invest New Drugs, vol. 30, no. 5, pp. 1917-1925, 2012.

[204] J. Dong, Y. Li, H. Xiao et al., "Cordycepin sensitizes breast cancer cells toward irradiation through elevating ROS production involving Nrf2," Toxicology and Applied Pharmacology, vol. 364, pp. 12-21, 2019.

[205] V. P. Androutsopoulos, K. Ruparelia, R. R. Arroo, A. M. Tsatsakis, and D. A. Spandidos, "CYP1-mediated antiproliferative activity of dietary flavonoids in MDA-MB468 breast cancer cells," Toxicology, vol. 264, no. 3, pp. 162-170, 2009.

[206] H. W. Zhang, J. J. Hu, R. Q. Fu et al., "Flavonoids inhibit cell proliferation and induce apoptosis and autophagy through downregulation of PI3Kgamma mediated PI3K/AKT/ $\mathrm{mTOR} / \mathrm{p} 70 \mathrm{S6K} / \mathrm{ULK}$ signaling pathway in human breast cancer cells," Scientific Reports, vol. 8, no. 1, p. 11255, 2018.

[207] Y. Li, J. Hong, H. Li et al., "Genkwanin nanosuspensions: a novel and potential antitumor drug in breast carcinoma therapy," Drug Delivery, vol. 24, no. 1, pp. 1491-1500, 2017.

[208] Q. Wu, P. A. Kroon, H. Shao, P. W. Needs, and X. Yang, "Differential effects of quercetin and two of its derivatives, isorhamnetin and isorhamnetin-3-glucuronide, in inhibiting the proliferation of human breast-cancer MCF-7 cells," Journal of Agricultural and Food Chemistry, vol. 66, no. 27, pp. 7181-7189, 2018.

[209] C. Li, D. Yang, Y. Zhao et al., "Inhibitory effects of isorhamnetin on the invasion of human breast carcinoma cells by downregulating the expression and activity of matrix metalloproteinase-2/9," Nutrition and Cancer, vol. 67, no. 7, pp. 1191-1200, 2015.

[210] J. Hu, Y. Zhang, X. Jiang et al., "ROS-mediated activation and mitochondrial translocation of CaMKII contributes to Drp1-dependent mitochondrial fission and apoptosis in triple-negative breast cancer cells by isorhamnetin and chloroquine," Journal of Experimental \& Clinical Cancer Research, vol. 38, no. 1, p. 225, 2019.

[211] A. Alvarez-Sala, A. Attanzio, L. Tesoriere, G. Garcia-Llatas, R. Barbera, and A. Cilla, "Apoptotic effect of a phytosterolingredient and its main phytosterol (beta-sitosterol) in human cancer cell lines," International Journal of Food Sciences and Nutrition, vol. 70, no. 3, pp. 323-334, 2019.

[212] C. Park, D. O. Moon, C. H. Ryu et al., "Beta-sitosterol sensitizes MDA-MB-231 cells to TRAIL-induced apoptosis," Acta Pharmacologica Sinica, vol. 29, no. 3, pp. 341-348, 2008.

[213] A. B. Awad, R. Roy, and C. S. Fink, "Beta-sitosterol, a plant sterol, induces apoptosis and activates key caspases in MDAMB-231 human breast cancer cells," Oncology Reports, vol. 10, no. 2, pp. 497-500, 2003.

[214] A. B. Awad, A. C. Downie, and C. S. Fink, "Inhibition of growth and stimulation of apoptosis by beta-sitosterol treatment of MDA-MB-231 human breast cancer cells in 
culture," International Journal of Molecular Medicine, vol. 5, no. 5, pp. 541-545, 2000.

[215] A. B. Awad, S. L. Barta, C. S. Fink, and P. G. Bradford, "betaSitosterol enhances tamoxifen effectiveness on breast cancer cells by affecting ceramide metabolism," Molecular Nutrition \& Food Research, vol. 52, no. 4, pp. 419-426, 2008.

[216] C. Azevedo, A. Correia-Branco, J. R. Araujo, J. T. Guimaraes, E. Keating, and F. Martel, "The chemopreventive effect of the dietary compound kaempferol on the MCF-7 human breast cancer cell line is dependent on inhibition of glucose cellular uptake," Nutrition and Cancer, vol. 67, no. 3, pp. 504-513, 2015.

[217] S. Y. Chien, Y. C. Wu, J. G. Chung et al., "Quercetin-induced apoptosis acts through mitochondrial- and caspase-3-dependent pathways in human breast cancer MDA-MB-231 cells," Human \& Experimental Toxicology, vol. 28, no. 8, pp. 493-503, 2009.

[218] E. J. Choi and W. S. Ahn, "Kaempferol induced the apoptosis via cell cycle arrest in human breast cancer MDA-MB-453 cells," Nutrition Research and Practice, vol. 2, no. 4, pp. 322-325, 2008.

[219] C. C. Chou, J. S. Yang, H. F. Lu et al., "Quercetin-mediated cell cycle arrest and apoptosis involving activation of a caspase cascade through the mitochondrial pathway in human breast cancer MCF-7 cells," Archives of Pharmacal Research, vol. 33, no. 8, pp. 1181-1191, 2010.

[220] M. T. Cook, Y. Liang, C. Besch-Williford, S. Goyette, B. Mafuvadze, and S. M. Hyder, "Luteolin inhibits progestindependent angiogenesis, stem cell-like characteristics, and growth of human breast cancer xenografts," Springerplus, vol. 4, p. 444, 2015.

[221] M. T. Cook, Y. Liang, C. Besch-Williford, and S. M. Hyder, "Luteolin inhibits lung metastasis, cell migration, and viability of triple-negative breast cancer cells," Breast Cancer (Dove Med Press), vol. 9, pp. 9-19, 2017.

[222] X. H. Deng, H. Y. Song, Y. F. Zhou, G. Y. Yuan, and F. J. Zheng, "Effects of quercetin on the proliferation of breast cancer cells and expression of survivin in vitro," Experimental and Therapeutic Medicine, vol. 6, no. 5, pp. 1155-1158, 2013.

[223] J. Duo, G. G. Ying, G. W. Wang, and L. Zhang, "Quercetin inhibits human breast cancer cell proliferation and induces apoptosis via Bcl-2 and Bax regulation," Molecular Medicine Reports, vol. 5, no. 6, pp. 1453-1456, 2012.

[224] G. Gao, R. Ge, Y. Li, and S. Liu, "Luteolin exhibits anti-breast cancer property through up-regulating miR-203," Artificial Cells, Nanomedicine, and Biotechnology, vol. 47, no. 1, pp. 3265-3271, 2019.

[225] L. Huang, K. Jin, and H. Lan, "Luteolin inhibits cell cycle progression and induces apoptosis of breast cancer cells through downregulation of human telomerase reverse transcriptase," Oncology Letters, vol. 17, no. 4, pp. 38423850, 2019.

[226] H. Hung, "Inhibition of estrogen receptor alpha expression and function in MCF-7 cells by kaempferol," Journal of Cellular Physiology, vol. 198, no. 2, pp. 197-208, 2004.

[227] L. Jia, S. Huang, X. Yin, Y. Zan, Y. Guo, and L. Han, "Quercetin suppresses the mobility of breast cancer by suppressing glycolysis through Akt-mTOR pathway mediated autophagy induction," Life Sciences, vol. 208, pp. 123$130,2018$.

[228] Y. Jiang, K. P. Xie, H. N. Huo, L. M. Wang, W. Zou, and M. J. Xie, "[Inhibitory effect of luteolin on the angiogenesis of chick chorioallantoic membrane and invasion of breast cancer cells via downregulation of AEG-1 and MMP-2]," Sheng Li Xue Bao, vol. 65, no. 5, pp. 513-518, 2013.

[229] G. Y. Kang, E. R. Lee, J. H. Kim et al., "Downregulation of PLK-1 expression in kaempferol-induced apoptosis of MCF7 cells," European Journal of Pharmacology, vol. 611, no. 1-3, pp. 17-21, 2009.

[230] B. W. Kim, E. R. Lee, H. M. Min et al., "Sustained ERK activation is involved in the kaempferol-induced apoptosis of breast cancer cells and is more evident under 3-D culture condition," Cancer Biology \& Therapy, vol. 7, no. 7, pp. 1080-1089, 2008.

[231] M. J. Kim, J. S. Woo, C. H. Kwon, J. H. Kim, Y. K. Kim, and K. H. Kim, "Luteolin induces apoptotic cell death through AIF nuclear translocation mediated by activation of ERK and p38 in human breast cancer cell lines," Cell Biology International, vol. 36, no. 4, pp. 339-344, 2012.

[232] S. H. Kim, K. A. Hwang, and K. C. Choi, "Treatment with kaempferol suppresses breast cancer cell growth caused by estrogen and triclosan in cellular and xenograft breast cancer models," Journal of Nutritional Biochemistry, vol. 28, pp. 70-82, 2016.

[233] E. J. Lee, S. Y. Oh, and M. K. Sung, "Luteolin exerts antitumor activity through the suppression of epidermal growth factor receptor-mediated pathway in MDA-MB-231 ERnegative breast cancer cells," Food and Chemical Toxicology, vol. 50, no. 11, pp. 4136-4143, 2012.

[234] G. A. Lee, K. C. Choi, and K. A. Hwang, "Kaempferol, a phytoestrogen, suppressed triclosan-induced epithelialmesenchymal transition and metastatic-related behaviors of MCF-7 breast cancer cells," Environmental Toxicology and Pharmacology, vol. 49, pp. 48-57, 2017.

[235] Y. K. Lee, S. Y. Park, Y. M. Kim, W. S. Lee, and O. J. Park, "AMP kinase/cyclooxygenase-2 pathway regulates proliferation and apoptosis of cancer cells treated with quercetin," Experimental \& Molecular Medicine, vol. 41, no. 3, pp. 201-207, 2009.

[236] C. Li, Y. Zhao, D. Yang et al., "Inhibitory effects of kaempferol on the invasion of human breast carcinoma cells by downregulating the expression and activity of matrix metalloproteinase-9," Biochemistry and Cell Biology, vol. 93, no. 1, pp. 16-27, 2015

[237] S. Li, Q. Zhao, B. Wang, S. Yuan, X. Wang, and K. Li, "Quercetin reversed MDR in breast cancer cells through down-regulating $\mathrm{P}$-gp expression and eliminating cancer stem cells mediated by YB-1 nuclear translocation," Phytotherapy Research, vol. 32, no. 8, pp. 1530-1536, 2018.

[238] X. Li, N. Zhou, J. Wang et al., "Quercetin suppresses breast cancer stem cells (CD44(+)/CD24(-)) by inhibiting the PI3K/Akt/mTOR-signaling pathway," Life Sciences, vol. 196, pp. 56-62, 2018.

[239] C. H. Lin, C. Y. Chang, K. R. Lee, H. J. Lin, T. H. Chen, and L. Wan, "Flavones inhibit breast cancer proliferation through the Akt/FOXO3a signaling pathway," BMC Cancer, vol. 15, p. 958, 2015.

[240] C. W. Lin, W. C. Hou, S. C. Shen et al., "Quercetin inhibition of tumor invasion via suppressing PKC delta/ERK/AP-1dependent matrix metalloproteinase- 9 activation in breast carcinoma cells," Carcinogenesis, vol. 29, no. 9, pp. 18071815, 2008.

[241] D. Lin, G. Kuang, J. Wan et al., "Luteolin suppresses the metastasis of triple-negative breast cancer by reversing epithelial-to-mesenchymal transition via downregulation of beta-catenin expression," Oncology Reports, vol. 37, no. 2, pp. 895-902, 2017. 
[242] B. M. Markaverich, K. Shoulars, and M. A. Rodriguez, "Luteolin regulation of estrogen signaling and cell cycle pathway genes in MCF-7 human breast cancer cells," International Journal of Biomedical Science, vol. 7, no. 2, pp. 101-111, 2011.

[243] L. T. Nguyen, Y. H. Lee, A. R. Sharma et al., "Quercetin induces apoptosis and cell cycle arrest in triple-negative breast cancer cells through modulation of Foxo3a activity," The Korean Journal of Physiology \& Pharmacology, vol. 21, no. 2, pp. 205-213, 2017.

[244] S. M. Oh, Y. P. Kim, and K. H. Chung, "Biphasic effects of kaempferol on the estrogenicity in human breast cancer cells," Archives of Pharmacal Research, vol. 29, no. 5, pp. 354-362, 2006.

[245] S. H. Park, S. Ham, T. H. Kwon et al., "Luteolin induces cell cycle arrest and apoptosis through extrinsic and intrinsic signaling pathways in MCF-7 breast cancer cells," Journal of Environmental Pathology, Toxicology, and Oncology, vol. 33, no. 3, pp. 219-231, 2014.

[246] K. Phromnoi, S. Yodkeeree, S. Anuchapreeda, and P. Limtrakul, "Inhibition of MMP-3 activity and invasion of the MDA-MB-231 human invasive breast carcinoma cell line by bioflavonoids," Acta Pharmacologica Sinica, vol. 30, no. 8, pp. 1169-1176, 2009.

[247] S. Ranganathan, D. Halagowder, and N. D. Sivasithambaram, "Quercetin suppresses twist to induce apoptosis in MCF-7 breast cancer cells," PLoS One, vol. 10, no. 10, Article ID e0141370, 2015.

[248] P. S. Rao, A. Satelli, M. Moridani, M. Jenkins, and U. S. Rao, "Luteolin induces apoptosis in multidrug resistant cancer cells without affecting the drug transporter function: involvement of cell line-specific apoptotic mechanisms," International Journal of Cancer, vol. 130, no. 11, pp. 2703-2714, 2012.

[249] K. M. Reipas, J. H. Law, N. Couto et al., "Luteolin is a novel p90 ribosomal S6 kinase (RSK) inhibitor that suppresses Notch 4 signaling by blocking the activation of Y-box binding protein-1 (YB-1)," Oncotarget, vol. 4, no. 2, pp. 329-345, 2013.

[250] A. Rivera Rivera, L. Castillo-Pichardo, Y. Gerena, and S. Dharmawardhane, "Anti-breast cancer potential of quercetin via the Akt/AMPK/mammalian target of rapamycin (mTOR) signaling cascade," PLoS One, vol. 11, no. 6, Article ID e0157251, 2016.

[251] G. Scambia, F. O. Ranelletti, P. Benedetti Panici et al., "Quercetin inhibits the growth of a multidrug-resistant estrogen-receptor-negative MCF-7 human breast-cancer cell line expressing type II estrogen-binding sites," Cancer Chemotherapy and Pharmacology, vol. 28, no. 4, pp. 255258, 1991.

[252] H. S. Seo, J. M. Ku, H. S. Choi et al., "Quercetin induces caspase-dependent extrinsic apoptosis through inhibition of signal transducer and activator of transcription 3 signaling in HER2-overexpressing BT-474 breast cancer cells," Oncology Reports, vol. 36, no. 1, pp. 31-42, 2016.

[253] A. Srinivasan, C. Thangavel, Y. Liu et al., "Quercetin regulates beta-catenin signaling and reduces the migration of triple negative breast cancer," Including results for $\mathrm{Mol}$ Carcinogenesis, vol. 55, no. 5, pp. 743-756, 2015.

[254] J. Q. Sui, K. P. Xie, and M. J. Xie, "Inhibitory effect of luteolin on the proliferation of human breast cancer cell lines induced by epidermal growth factor," Sheng Li Xue Bao, vol. 68, no. 1, pp. 27-34, 2016.
[255] D. W. Sun, H. D. Zhang, L. Mao et al., "Luteolin inhibits breast cancer development and progression in vitro and in vivo by suppressing Notch signaling and regulating MiRNAs," Cellular Physiology and Biochemistry, vol. 37, no. 5, pp. 1693-1711, 2015.

[256] S. F. Tao, H. F. He, and Q. Chen, "Quercetin inhibits proliferation and invasion acts by up-regulating miR-146a in human breast cancer cells," Molecular and Cellular Biochemistry, vol. 402, no. 1-2, pp. 93-100, 2015.

[257] L. M. Wang, K. P. Xie, H. N. Huo, F. Shang, W. Zou, and M. J. Xie, "Luteolin inhibits proliferation induced by IGF-1 pathway dependent ERalpha in human breast cancer MCF-7 cells," Asian Pacific Journal of Cancer Prevention, vol. 13, no. 4, pp. 1431-1437, 2012.

[258] R. Wang, L. Yang, S. Li et al., "Quercetin inhibits breast cancer stem cells via downregulation of aldehyde dehydrogenase 1A1 (ALDH1A1), chemokine receptor type 4 (CXCR4), mucin 1 (MUC1), and epithelial cell adhesion molecule (EpCAM)," Medical Science Monitor, vol. 24, pp. 412-420, 2018.

[259] T. D. Way, M. C. Kao, and J. K. Lin, "Degradation of HER2/ neu by apigenin induces apoptosis through cytochrome $\mathrm{C}$ release and caspase-3 activation in HER2/neu-overexpressing breast cancer cells," FEBS Letters, vol. 579, no. 1, pp. 145-152, 2005.

[260] X. Yi, J. Zuo, C. Tan et al., "Kaempferol, a flavonoid compound from gynura medica induced apoptosis and growth inhibition in mcf-7 breast cancer cell," African Journal of Traditional, Complementary and Alternative Medicines, vol. 13, no. 4, pp. 210-215, 2016.

[261] X. Zhao, Q. Wang, S. Yang et al., "Quercetin inhibits angiogenesis by targeting calcineurin in the xenograft model of human breast cancer," European Journal of Pharmacology, vol. 781, pp. 60-68, 2016.

[262] L. Zhu and L. Xue, "Kaempferol suppresses proliferation and induces cell cycle arrest, apoptosis, and DNA damage in breast cancer cells," Oncology Research, vol. 27, no. 6, pp. 629-634, 2019.

[263] Y.-K. Lee, S. Y. Park, W.-S. L. Young-Min Kim, and O. Park, "Regulation of MCF-7 cell apoptosis by phytochemical quercetin through AMPK-mTOR signaling pathway," Cancer Prevention Research, vol. 15, no. 4, pp. 320-325.

[264] Y. Pandey, S. H. Mehdi, M. A. Khan, P. Bhatt, and C. Pant, "TRAIL (Tumor Necrosis Factor-Related Apoptosis-Inducing Ligand) mediated Apoptosis of human breast cancer cells sensitized by dietary flavonoid Kaempferol," International Journal of Biological Sciences, vol. 5, p. 6, 2019.

[265] J. Stapel, C. Oppermann, D. Richter, W. Ruth, and V. J. Briese, "Polyphenol compounds with anti-carcinogenic qualities: effects of quercetin (flavonol), chrysin (flavon), kaempferol (flavanol), naringenin (flavanon) and hesperidin (flavanoid) on in vitro breast cancer," J Journal of Medicinal Plants Research, vol. 7, no. 29, pp. 2187-2196, 2013.

[266] A. S. Sultan, M. I. Khalil, B. M. Sami, A. F. Alkhuriji, and O. J. Sadek, "Quercetin induces apoptosis in triple-negative breast cancer cells via inhibiting fatty acid synthase and $\beta$-catenin," International Journal of Clinical and Experimental Pathology, vol. 10, no. 1, pp. 156-172, 2017.

[267] S. H. Akbas, M. Timur, and T. Ozben, "The effect of quercetin on topotecan cytotoxicity in MCF-7 and MDAMB 231 human breast cancer cells," Journal of Surgical Research, vol. 125, no. 1, pp. 49-55, 2005.

[268] C. T. Chiang, T. D. Way, and J. K. Lin, "Sensitizing HER2overexpressing cancer cells to luteolin-induced apoptosis 
through suppressing p21(WAF1/CIP1) expression with rapamycin," Molecular Cancer Therapeutics, vol. 6, no. 7, pp. 2127-2138, 2007.

[269] G. Du, H. Lin, M. Wang et al., "Quercetin greatly improved therapeutic index of doxorubicin against $4 \mathrm{~T} 1$ breast cancer by its opposing effects on HIF-1alpha in tumor and normal cells," Cancer Chemotherapy and Pharmacology, vol. 65, no. 2, pp. 277-287, 2010.

[270] G. J. Du, Z. H. Song, H. H. Lin, X. F. Han, S. Zhang, and Y. M. Yang, "Luteolin as a glycolysis inhibitor offers superior efficacy and lesser toxicity of doxorubicin in breast cancer cells," Biochemical and Biophysical Research Communications, vol. 372, no. 3, pp. 497-502, 2008.

[271] Y. W. Jeon, Y. E. Ahn, W. S. Chung, H. J. Choi, and Y. J. Suh, "Synergistic effect between celecoxib and luteolin is dependent on estrogen receptor in human breast cancer cells," Tumor Biology, vol. 36, no. 8, pp. 6349-6359, 2015.

[272] Y. W. Jeon and Y. J. Suh, "Synergistic apoptotic effect of celecoxib and luteolin on breast cancer cells," Oncology Reports, vol. 29, no. 2, pp. 819-825, 2013.

[273] M. R. Kim, H. S. Choi, J. W. Yang, B. C. Park, J. A. Kim, and K. W. Kang, "Enhancement of vascular endothelial growth factor-mediated angiogenesis in tamoxifen-resistant breast cancer cells: role of Pin1 overexpression," Molecular Cancer Therapeutics, vol. 8, no. 8, pp. 2163-2171, 2009.

[274] S. Li, S. Yuan, Q. Zhao, B. Wang, X. Wang, and K. Li, "Quercetin enhances chemotherapeutic effect of doxorubicin against human breast cancer cells while reducing toxic side effects of it," Biomedicine \& Pharmacotherapy, vol. 100, pp. 441-447, 2018.

[275] S. Z. Li, S. F. Qiao, J. H. Zhang, and K. Li, "Quercetin increase the chemosensitivity of breast cancer cells to doxorubicin via PTEN/Akt pathway," Anti-Cancer Agents in Medicinal Chemistry, vol. 15, no. 9, pp. 1185-1189, 2015.

[276] H. Liu, J. I. Lee, and T. G. Ahn, "Effect of quercetin on the anti-tumor activity of cisplatin in EMT6 breast tumorbearing mice," Obstetrics \& Gynecology Science, vol. 62, no. 4, pp. 242-248, 2019.

[277] N. Orsolic and N. Car, "Quercetin and hyperthermia modulate cisplatin-induced DNA damage in tumor and normal tissues in vivo," Tumor Biology, vol. 35, no. 7, pp. 6445-6454, 2014.

[278] R. Sharma, L. Gatchie, I. S. Williams et al., "Glycyrrhiza glabra extract and quercetin reverses cisplatin resistance in triple-negative MDA-MB-468 breast cancer cells via inhibition of cytochrome P450 1B1 enzyme," Bioorganic \& Medicinal Chemistry Letters, vol. 27, no. 24, pp. 5400-5403, 2017.

[279] S. H. Tu, C. T. Ho, M. F. Liu et al., "Luteolin sensitises drugresistant human breast cancer cells to tamoxifen via the inhibition of cyclin E2 expression," Food Chemistry, vol. 141, no. 2, pp. 1553-1561, 2013.

[280] H. Wang, L. Tao, K. Qi et al., "Quercetin reverses tamoxifen resistance in breast cancer cells," Journal of B.U.ON.: Official Journal of the Balkan Union of Oncology, vol. 20, no. 3, pp. 707-713, 2015.

[281] M. Y. Wong and G. N. Chiu, "Simultaneous liposomal delivery of quercetin and vincristine for enhanced estrogenreceptor-negative breast cancer treatment," Anticancer Drugs, vol. 21, no. 4, pp. 401-410, 2010.

[282] M. Y. Wong and G. N. Chiu, "Liposome formulation of coencapsulated vincristine and quercetin enhanced antitumor activity in a trastuzumab-insensitive breast tumor xenograft model," Nanomedicine, vol. 7, no. 6, pp. 834-840, 2011.
[283] M. Y. Yang, C. J. Wang, N. F. Chen, W. H. Ho, F. J. Lu, and T. H. Tseng, "Luteolin enhances paclitaxel-induced apoptosis in human breast cancer MDA-MB-231 cells by blocking STAT3," Chemico-Biological Interactions, vol. 213, pp. 60-68, 2014.

[284] L. Zhang, F. Yang, L. Huang, A. Liu, and J. Zhang, "Luteolin enhances the antitumor activity of lapatinib in human breast cancer cells," Biomed Res, vol. 28, no. 11, pp. 4902-4907, 2017.

[285] S. Soltanian, H. Riahirad, A. Pabarja, M. R. Karimzadeh, and K. J. B. Saeidi, "Kaempferol and docetaxel diminish side population and down-regulate some cancer stem cell markers in breast cancer cell line MCF-7," Biocell, vol. 41, no. $2 \& 3$, p. 33, 2018.

[286] M. Louisa and B. Wardhani, "Quercetin improves the efficacy of sorafenib in triple negative breast cancer cells through the modulation of drug efflux transporters expressions," International Journal of Applied Pharmaceutics, vol. 11, pp. 129-134, 2019.

[287] M. L. Ackland, S. van de Waarsenburg, and R. Jones, "Synergistic antiproliferative action of the flavonols quercetin and kaempferol in cultured human cancer cell lines," In Vivo, vol. 19, no. 1, pp. 69-76, 2005.

[288] Y. L. Shih, H. C. Liu, C. S. Chen et al., "Combination treatment with luteolin and quercetin enhances antiproliferative effects in nicotine-treated MDA-MB-231 cells by down-regulating nicotinic acetylcholine receptors," Journal of Agricultural and Food Chemistry, vol. 58, no. 1, pp. 235-241, 2009.

[289] P. Knekt, J. Kumpulainen, R. Jarvinen et al., "Flavonoid intake and risk of chronic diseases," The American Journal of Clinical Nutrition, vol. 76, no. 3, pp. 560-568, 2002.

[290] U. Vanhoefer, A. Harstrick, W. Achterrath, S. Cao, S. Seeber, and Y. M. Rustum, "Irinotecan in the treatment of colorectal cancer: clinical overview," Journal of Clinical Oncology, vol. 19, no. 5, pp. 1501-1518, 2001. 